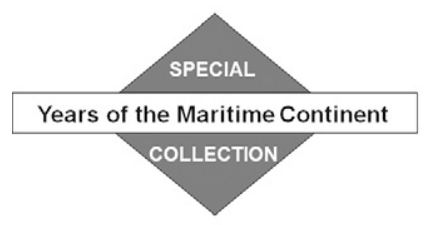

\title{
DVariation of Radar-Observed Precipitation Characteristics in Relation to the Simultaneous Passages of a Madden-Julian Oscillation Event and Convectively Coupled Equatorial Waves during the Years of the Maritime Continent Pilot Study
}

\author{
BiaO GENG ${ }^{\mathrm{a}}$ AND MASAKI KATSUMATA ${ }^{\mathrm{a}}$

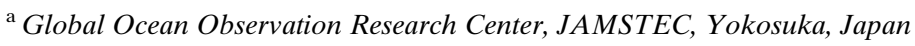

(Manuscript received 26 October 2020, in final form 24 July 2021)

\begin{abstract}
In this study, we examined the variations of precipitation morphology and rainfall in relation to the simultaneous passages of a Madden-Julian oscillation (MJO) event and convectively coupled equatorial waves (CCEWs) observed during the Years of the Maritime Continent pilot study. We utilized globally merged infrared brightness temperature data and the radiosonde and radar data observed aboard the Research Vessel Mirai at $4^{\circ} 4^{\prime} \mathrm{S}, 101^{\circ} 54^{\prime} \mathrm{E}$. As well as the observed MJO event, equatorial Rossby waves (ERWs), Kelvin waves (KWs), and mixed Rossby-gravity waves (MRGWs) were identified. The radar data exhibited high-frequency variation, mainly caused by KWs and MRGWs, and low-frequency variation, mainly caused by the MJO and ERWs. The MRGWs predominantly modulated convective echo areas and both convective and stratiform volumetric rainfall. In contrast, the MJO event had little influence on the variance of convective echoes. Moreover, stratiform echo areas and volumetric rainfall were more strongly modulated by the combined effects of the MJO, ERWs, KWs, and MRGWs than their convective counterparts. The intense development of stratiform echo areas and volumetric rainfall was coherent with the superimposition of the active phases of the MJO event and all the analyzed CCEWs. The strongest development and a significant reduction of convective echo-top heights before and after the peak MJO date, respectively, were coherent with the passages of ERWs and MRGWs, which were the dominant wave types in modulating echo-top heights. Thus, it appears that the superimposition of the CCEWs on the MJO event exerted complex modulations on the convective activities within the MJO event.
\end{abstract}

SIGNIFICANCE STATEMENT: To improve the understanding of the variation characteristics of precipitation associated with the Madden-Julian oscillation (MJO) superimposed by equatorial waves, we examined variations of precipitation morphology in relation to the simultaneous passages of an MJO event and equatorial Rossby, Kelvin, and mixed Rossby-gravity waves, which were observed near the west coast of Sumatra Island during the Years of the Maritime Continent pilot study. We found that the multiple time-scale variability of convective and stratiform precipitation was mainly associated with one or two types of equatorial waves, rather than the MJO event. This highlights that equatorial waves can be key factors in modulating the development and variability of convective activities within an MJO event.

KEYWORDS: Atmosphere; Maritime Continent; Madden-Julian oscillation; Precipitation

\section{Introduction}

Madden-Julian oscillation (MJO) events (Madden and Julian 1972) and convectively coupled equatorial waves (CCEWs) are large-scale propagating disturbances in the tropics. An MJO event is a dominant mode of tropical convective variability on intraseasonal time scales; its convective envelope has a spatial scale of a few thousand kilometers and propagates eastward over the Indo-Pacific warm pool (Zhang 2005; Jiang et al. 2020). CCEWs include equatorial Rossby waves (ERWs), Kelvin waves (KWs), mixed Rossby-gravity waves (MRGWs), eastward inertia-gravity waves (EIGWs), and westward inertia-

\footnotetext{
¿ Denotes content that is immediately available upon publication as open access.
}

Corresponding author: Biao Geng, bgeng@jamstec.go.jp gravity waves (WIGWs) (Wheeler et al. 2000; Kiladis et al. 2009). MJO and CCEW events largely modulate convective activities in tropical regions (Wheeler and Kiladis 1999; Roundy and Frank 2004a; Kiladis et al. 2005; Kiladis et al. 2009), thus exerting significant impacts on the variability of tropical rainfall. For example, Schlueter et al. (2019) found that rainfall over northern tropical Africa is modulated by KWs and tropical depression (TD)-type disturbances on a daily time scale, while it is affected by MJO events and ERWs on a time scale of 7-20 days. Furthermore, Lubis and Jacobi (2015) revealed that the variability of tropical precipitation modulated by CCEWs varies across seasons and locations.

The modulations of MJO events and CCEWs on rainfall variability could be attributed to their distinct influence on precipitation morphology. Barnes and Houze (2013) and Powell and Houze (2013) found that within MJO events, the variability of stratiform precipitation areas dominates the variability of convective precipitation areas. DePasquale et al. (2014) 
illustrated that the convective echo-top heights of MJO events maximize approximately 8 days before the peak MJO date. For rainfall variation during the active phases of the MJO, Lin et al. (2004) and Morita et al. (2006) revealed that the variation amplitude of stratiform rainfall is larger than that of convective rainfall. With regard to CCEWs, Swann et al. (2006) and Holder et al. (2008) compared the precipitation morphologies of KWs and MRGWs, indicating that KWs tend to contain larger total and stratiform precipitation areas than MRGWs. Further, Yasunaga and Mapes (2012) indicated that KWs, EIGWs, and WIGWs preferentially modulate mesoscale convective systems (MCSs) with extended stratiform precipitation, whereas ERWs, MRGWs, and TDs mainly modulate convective precipitation and smaller-sized precipitation systems.

It has long been known that the MJO convective envelope is frequently superimposed by CCEWs (Nakazawa 1988). Considerable attention has been paid to the interactions between MJO events and CCEWs (Dickinson and Molinari 2002; Straub and Kiladis 2003; Roundy 2008; Masunaga 2009; Guo et al. 2014). Particularly, it has been pointed out that ERWs and MRGWs can generate MJO events (Roundy and Frank 2004b; Yang and Ingersoll 2011). In contrast, precipitation morphology and its variation within MJO events superimposed by CCEWs remain largely uninvestigated. Only a limited number of studies have emphasized the impact of CCEWs on precipitation within the convective envelope of the MJO. MacRitchie and Roundy (2012) found that $62 \%$ of the total rainfall and $46 \%$ of the total rain area within the MJO observed in the Indian Ocean occur within the active phases of KWs. Gottschalck et al. (2013) noted that during the Dynamics of the Madden-Julian Oscillation (DYNAMO) field campaign, the active phases of KWs played a significant role in enhancing rainfall within the convective envelope of one MJO event, whereas the strongly suppressed phase of a KW suppressed convection and rainfall during the active phase of another MJO event. Powell and Houze (2013) and Zuluaga and Houze (2013) showed that convective precipitation and rainfall during the active phases of the MJO events of DYNAMO exhibit high-frequency variation on a time scale of 2-4 days, which probably corresponds to the superimposition of WIGWs on an MJO environment.

When CCEWs are superimposed on an MJO event, the associated precipitation morphology and rainfall are dictated by the effects of the MJO and CCEWs in different combinations. However, the relative modulations of the MJO and CCEWs on the variances of precipitation morphology and rainfall have not yet been documented for an MJO event superimposed by CCEWs. To fully characterize the precipitation associated with such an event, it is necessary to improve our knowledge of the effects of various modulations of the MJO event and CCEWs on precipitation within an MJO event. The improved knowledge will further be useful for evaluating MJO simulations by general circulation models (GCMs), which still face significant problems in reproducing the observed precipitation variances associated with MJO events and CCEWs (Lin et al. 2006; Guo et al. 2015).

A stationary observation was conducted on the Research Vessel Mirai located near the west coast of Sumatra Island during the field campaign of the Years of the Maritime Continent (YMC) pilot study (Pre-YMC) (Yoneyama and Zhang 2020). As indicated by Yoneyama and Zhang (2020), the vigorous convective activity around the Indo-Pacific Maritime
Continent (MC) is modulated by various phenomena, including diurnally evolving convection, CCEWs, and MJO events. The $\mathrm{MC}$ is also known as a barrier to $\mathrm{MJO}$ propagation, as an $\mathrm{MJO}$ will often weaken or fail when it reaches the MC. In particular, during the boreal winter, the deep convection of eastwardpropagating MJO events frequently detours around the $\mathrm{MC}$ and propagates through the oceanic region between Indonesia and Australia (Wu and Hsu 2009; Kim et al. 2017; Zhang and Ling 2017). It has been revealed that CCEWs have great impacts on MJO propagation in the MC region (Feng et al. 2015; DeMott et al. 2018; Zhu et al. 2019). Jiang et al. (2020) reviewed several factors that have been proposed by previous studies to be responsible for the barrier effect of the MC, including topographic effects, land surface processes, local diurnal convection cycles, and regional- and large-scale mean moisture distributions around the MC. However, as indicated by Jiang et al. (2020), current GCMs suffer from poor representation of the behavior of the MJO as it propagates over the $\mathrm{MC}$, indicating that the basic physical process of the MC barrier effect on MJO events is still poorly understood.

The stationary observation of the Mirai during the Pre-YMC campaign was conducted at $4^{\circ} 4^{\prime} \mathrm{S}, 101^{\circ} 54^{\prime} \mathrm{E}$ over a period extending from 1200 UTC 23 November to 1200 UTC 17 December 2015, when the convective envelope of an MJO event, as well as several ERWs, KWs, and MRGWs, traversed the observational site. Although the diurnal cycle of precipitation observed during the Pre-YMC campaign has been investigated by previous studies (Yokoi et al. 2017; Geng et al. 2020), the relationships between the variations of precipitation morphology and the MJO and CCEW events during this period remain unclear. The purpose of this study is, therefore, to examine the precipitation characteristics observed by a C-band polarimetric radar aboard the Research Vessel Mirai and to investigate the impact of an MJO event and three equatorial wave types on the variances of precipitation morphology and rainfall within the MJO event. Section 2 describes the data and methodology. Sections 3 and 4 describe the passages of the largescale disturbances and the variation characteristics of the radarderived variables, respectively, during the Pre-YMC. Section 5 analyzes the relationships between the radar-derived variables and large-scale disturbances. A discussion of the results is provided in section 6 , followed by the summary and conclusions in section 7 .

\section{Data and methodology}

\section{a. Data}

This study used the globally merged infrared brightness temperature $\left(T_{b}\right)$ data from the National Aeronautics and Space Administration (Janowiak et al. 2001) and the radiosonde and radar data observed aboard the Research Vessel Mirai. The reader is referred to Yoneyama and Zhang (2020) for information regarding the availability of the radiosonde and radar data. The time interval of the $T_{b}$ data was $30 \mathrm{~min}$. In addition, the radiosonde observations were conducted on a 3-hourly basis, and the shipborne polarimetric radar performed volume scans every $6 \mathrm{~min}$. The reader is referred to Geng and Katsumata (2020) for the main specifications of the Mirai polarimetric radar. The $T_{b}$ and radiosonde data were used to identify MJO and CCEW characteristics. Precipitation characteristics were simultaneously investigated using radar-derived variables. 


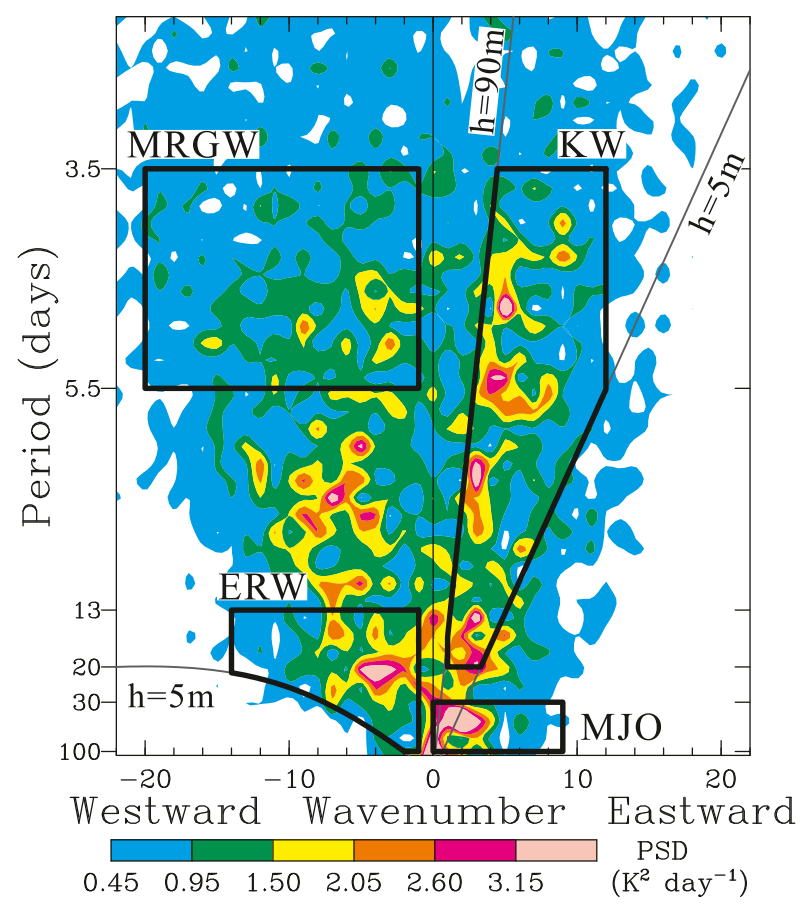

FIG. 1. Wavenumber-frequency power spectral density of the globally merged infrared brightness temperature $T_{b}$ (color shades), summed from $15^{\circ} \mathrm{S}$ to $15^{\circ} \mathrm{N}$ for October 2015-January 2016. Heavy solid boxes indicate the filter bands used to isolate the signals of the $\mathrm{MJO}$ and equatorial waves. The theoretical KW dispersion curves for the equivalent depths of $h=5$ and $90 \mathrm{~m}$ and the theoretical ERW dispersion curve for an equivalent depth of $h=5 \mathrm{~m}$ are superimposed. A 1-day running mean was applied to the $T_{b}$ data before spectral calculations.

\section{b. Identification of the MJO and CCEWS}

For statistical analysis, the $T_{b}$ data were downgraded from their native 30 -min resolution to an hourly resolution. To isolate the signals of the MJO event and CCEWs, we applied a filtering criterion in the wavenumber-frequency domain (Wheeler and Kiladis 1999; Wheeler et al. 2000). Figure 1 shows the wavenumber-frequency power spectral density of $T_{b}$ for the period from October 2015 to January 2016. As described by Straub and Kiladis (2002) and Roundy and Schreck (2009), the filtering criterion was applied to the raw data, without decomposing them into symmetric and antisymmetric equatorial wave components. The power spectral density of the zonal and meridional wind components observed by radiosonde aboard the Mirai from 23 November to 17 December 2015 (Fig. 2) was also used as supplementary material in determining the filtering criterion of the periods.

As shown in Fig. 1, filter bands that encompassed the wavenumbers and periods of the enhanced spectral power values corresponding to each disturbance type were used. The MJO filter was bounded by the eastward wavenumbers $0-9$ and periods of 30 100 days. The ERW filter was bounded by the westward wavenumbers 1-14 and periods of 13-100 days, together with a low-end cutoff at an equivalent depth of $5 \mathrm{~m}$. The KW filter was bounded by the eastward wavenumbers 1-12, periods of 3.5-20 days, and
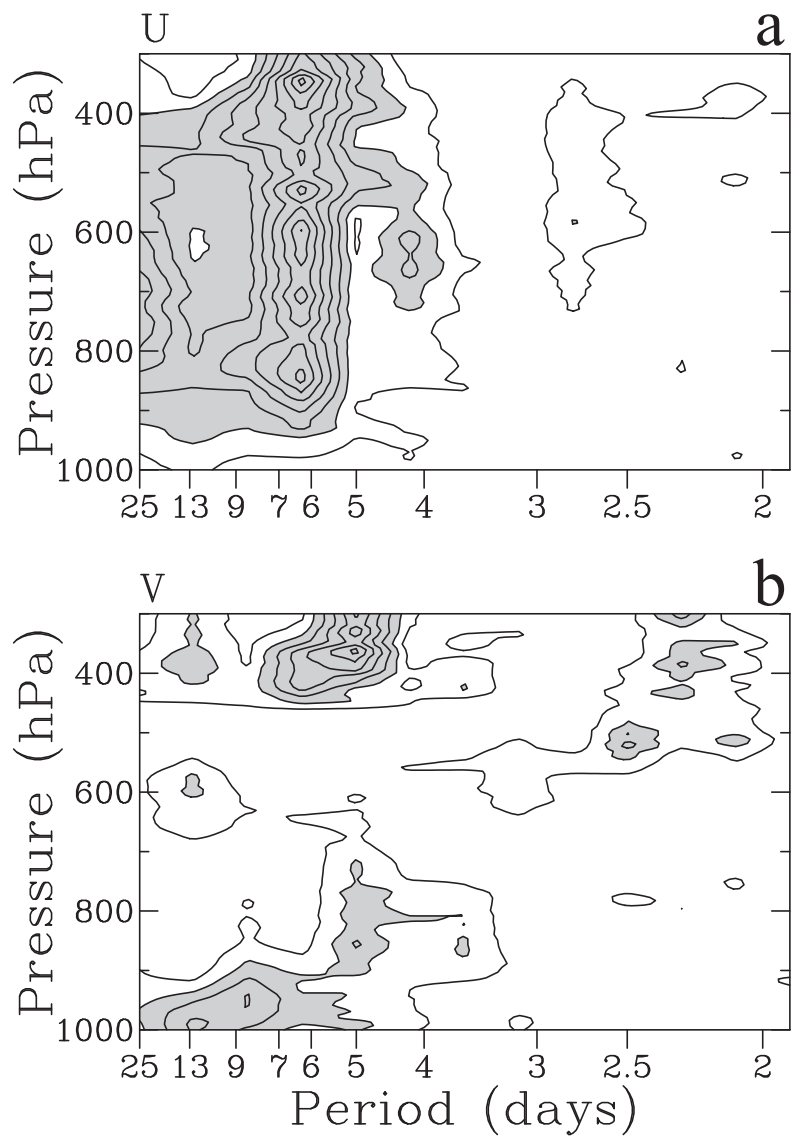

FIG. 2. (a) Power spectral density of the zonal wind component observed by radiosonde aboard the Research Vessel Mirai from 23 Nov to 17 Dec 2015. Contour interval is $0.2 \mathrm{~m}^{2} \mathrm{~s}^{-2} \mathrm{day}^{-1}$, with areas over $0.4 \mathrm{~m}^{2} \mathrm{~s}^{-2}$ day $^{-1}$ shaded in gray. (b) As in (a), but for the meridional wind component. Contour interval is $0.1 \mathrm{~m}^{2} \mathrm{~s}^{-2}$ day ${ }^{-1}$, with areas over $0.2 \mathrm{~m}^{2} \mathrm{~s}^{-2}$ day $^{-1}$ shaded in gray. A 1-day running mean was applied to the wind data before spectra calculations.

equivalent depths of 5 and $90 \mathrm{~m}$. The MRGW filter was bounded by the westward wavenumbers 1-20 and periods of 3.5-5.5 days.

The equivalent depth is a parameter closely related to the theoretical dispersive characteristics and structures of equatorial waves (Matsuno 1966). As indicated by Wheeler and Kiladis (1999), observed CCEWs are often dominated by theoretical equatorial wave signals over a range of equivalent depths. It is well known that MRGWs often evolve into off-equatorial TDs (Takayabu and Nitta 1993; Dickinson and Molinari 2002). The transition of MRGWs into TDs occurs on a continuum, with TDs possessing similar frequencies but higher wavenumbers than MRGWs (Wheeler and Kiladis 1999). Accordingly, the TD and MRGW signals in this study were merged rather than separated.

\section{c. Radar-derived variables}

First, quality control of the Mirai radar data was performed using the methods described by Geng and Katsumata (2020). Subsequently, the volume-scan data of the Mirai radar were interpolated onto Cartesian grids using a Cressman (1959) weighting scheme, with horizontal and vertical grid intervals of 
1 and $0.5 \mathrm{~km}$, respectively. The Cartesian-based radar volume covers $200 \times 200 \mathrm{~km}^{2}$ in the horizontal direction and $20 \mathrm{~km}$ in the vertical direction. The reflectivity data at an altitude of $2 \mathrm{~km}$ were used for convective-stratiform partitioning, rainfall estimation, and the identification of radar precipitation features (RPFs). The method described by Yuter and Houze (1998) was used to partition the echo into convective and stratiform components. Rainfall was estimated from radar reflectivity according to the rain rate-reflectivity $(Z-R)$ relationship developed by Yokoi et al. (2017). The $Z-R$ relationship was validated using comparisons between ground-based rain gauge data and the reflectivity data obtained by the Mirai radar during the PreYMC campaign. This study emphasizes the rainfall variability during the Mirai observational period. Although the rainfall estimation method used in this study was simplistic, tests of various $Z-R$ relationships revealed that the overall variation results of both convective and stratiform rainfall, in relation to the passages of the MJO and CCEWs, were less sensitive to the choice of $Z-R$ relationship (not shown). The RPFs were identified as contiguous radar pixels exceeding $10 \mathrm{dBZ}$. Based on Xu and Rutledge (2014; 2015), the RPFs were separated into MCSs $\left(\right.$ area $\left.\geq 1000 \mathrm{~km}^{2}\right)$ and sub-MCSs $\left(10 \mathrm{~km}^{2} \leq\right.$ area $\left.<1000 \mathrm{~km}^{2}\right)$.

Radar variables were derived at 1 -h intervals for subsequent statistical analyses, including time series of the hourly averaged echo areas of $\geq 10$ and $\geq 30 \mathrm{~dB} Z$ at $2 \mathrm{~km}$, the hourly averaged 10 and $30-\mathrm{dB} Z$ echo-top heights, the hourly averaged volumetric rainfall estimated from the echoes of $\geq 10 \mathrm{dBZ}$ at $2 \mathrm{~km}$, and the hourly averaged populations of MCSs and sub-MCSs within the coverage of the Cartesian-based radar data. Similar to previous studies (Barnes and Houze 2013; Zuluaga and Houze 2013), an echo threshold of $30 \mathrm{~dB} Z$ was used to capture the characteristics of more intense precipitation. These radar variables facilitate the investigation of both the horizontal and vertical development of precipitation, as well as the evolution of rainfall in association with convective activities. Similar to Xu et al. (2015), the 10- or 30-dBZ echo-top height in each grid was defined as the maximum height of the specified echo intensity in the column of the grid. Echo areas, echo-top heights, and volumetric rainfall values were derived for both convective and stratiform echoes.

Relationships between the radar-derived variables and the MJO, ERW, KW, and MRGW events were investigated by performing a simple linear regression (SLR) analysis and a standardized multiple linear regression (MLR) analysis. Each time series of the radarderived variables was regressed against the individual time indices of the MJO, ERW, KW, and MRGW events, with the indices of these large-scale disturbances defined in section 3 .

\section{Diagnosis of the MJO, ERWs, KWs, and MRGWs}

Figure 3 shows the time-longitude diagrams of the filtered $T_{b}$ anomalies for the period from 23 November to 31 December 2015. During this period, enhanced convective activities associated with an MJO event propagated through the central Indian and western Pacific Oceans (Fig. 3a). Later, this MJO event propagated to the central Pacific and circumnavigated the globe (not shown). Figure 3 a indicates that the convective activities associated with the MJO event propagated over the Mirai during its stationary observation. In addition to the eastward-moving MJO event, there were also a number of shorter-time-scale disturbances, which propagated either westward or eastward with time and were associated with either ERWs, KWs, or MRGWs (Figs. 3b-d). During the stationary observation of the Mirai, two ERWs, five KWs, and six MRGWs propagated across the observational site.

Figure 4 highlights the behavior of the MJO as it crossed the MC during the observational period of the Mirai. The convective activity associated with the MJO weakened near the equatorial region when it was crossing the MC. Simultaneously, the center of the MJO convective envelope shifted southward and propagated eastward through the oceanic region south of Sumatra and Java. These results reflect the typical MC barrier effect on MJO propagation during the boreal winter (Wu and Hsu 2009; Kim et al. 2017; Zhang and Ling 2017). Notably, with the southward detouring of the enhanced convective activity of the MJO around the equatorial MC islands, the convective activity of the MJO over the Mirai became relatively weak.

The space-time-filtered $T_{b}$ anomalies were reduced to time series by averaging around the Mirai from $101^{\circ}-103^{\circ} \mathrm{E}$ to $0^{\circ}-10^{\circ} \mathrm{S}$ (Fig. 5). In Fig. 5, the periods with negative and positive filtered $T_{b}$ anomalies are referred to as the active and suppressed phases, respectively. Figure 5 reveals more clearly that the passage of the MJO was superimposed by the passages of ERWs, KWs, and MRGWs. Evidently, these equatorial waves also overlapped with each other. The active phase of the MJO event started on 2 December and ended on 21 December (Fig. 5a). The MJO-filtered $\mathrm{T}_{\mathrm{b}}$ was minimized on 13 December, which is referred to as the peak MJO date. Figure 5a indicates that the convective activities leading up to and during the active phase of the MJO event were captured during the stationary observation of the Mirai. Based on previous studies (Yang et al. 2007; Kiladis et al. 2009), each time series of the filtered $T_{b}$ anomalies shown in Fig. 5 was used as the time index of the MJO event or a particular equatorial wave for subsequent regression and correlation analyses.

\section{Variation characteristics of the radar-derived variables}

Time series of the radar-derived variables of the echo areas, echo-top heights, and volumetric rainfall are shown in Fig. 6. Similar to the previous studies using the Mirai radar data collected during the Pre-YMC period (Yokoi et al. 2017; Geng et al. 2020), a pronounced diurnal cycle was observed in these radarderived variables. Besides the diurnal variation, the observational results of the Mirai radar exhibited several variations in precipitation closely related to the passages of the MJO event and CCEWs investigated in this study.

First, all the radar-derived variables shown in Fig. 6 varied on a time scale of 3-5 days. There were six to seven episodes when both the convective and stratiform echoes intensified in areal coverage, echo-top height, and volumetric rainfall. These enhanced episodes of convective activity peaked around 24,27 , and 30 November and 3, 7, 11, and 15 December, respectively. This 3-5-day variation was much shorter than the active phase of the MJO event (Fig. 5a) and is referred to as the high-frequency variation.

In addition, some of the radar-derived variables in Fig. 6 exhibited variations on a time scale of more than 10 days, which is referred to as the low-frequency variation. On a longer time scale, the $10-\mathrm{dBZ}$ stratiform echo areas at $2 \mathrm{~km}$ (Fig. $6 \mathrm{~b}$ ) tended to be enhanced around 30 November and 14 December, while they were 

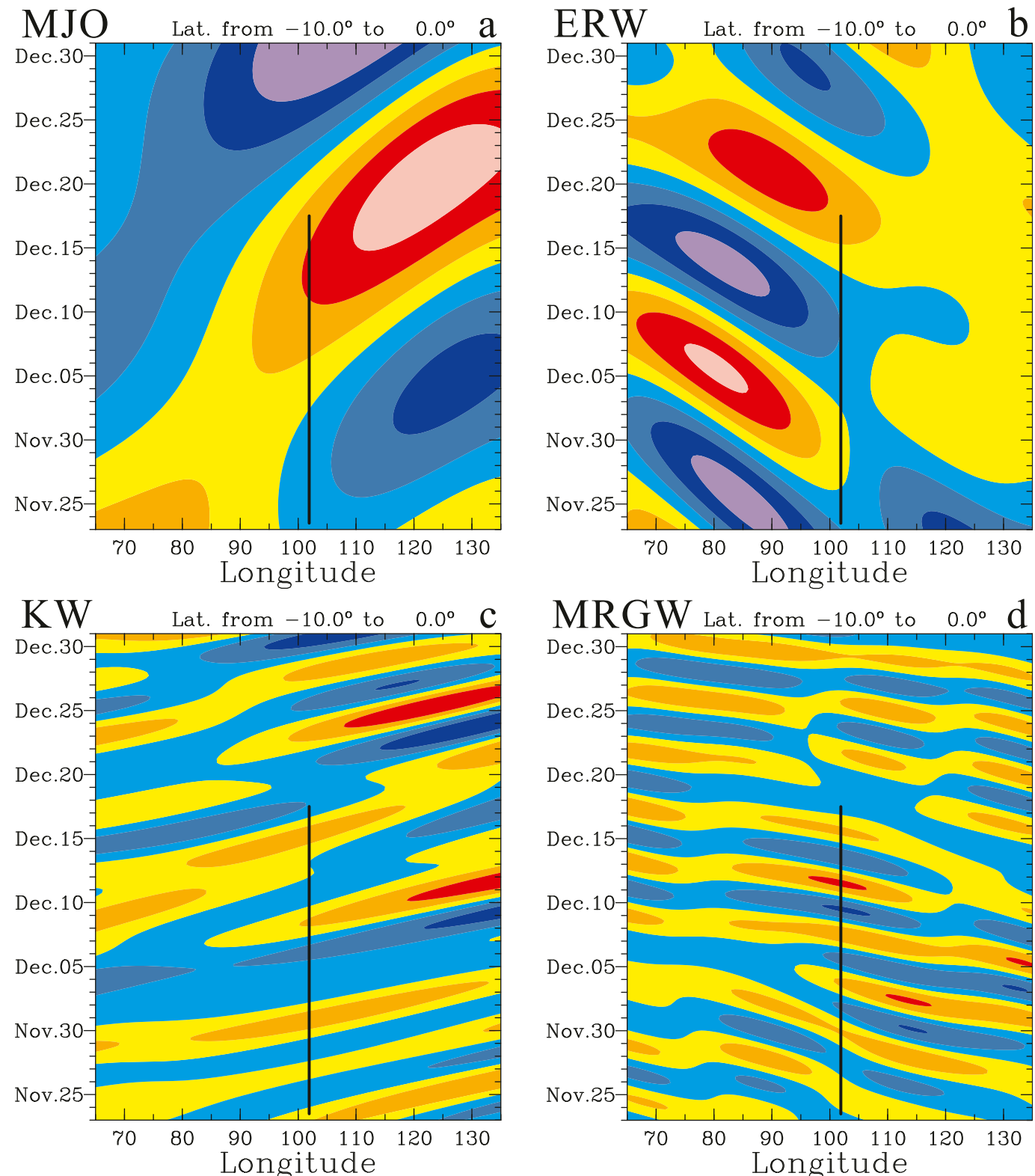

MRGW Lat. from $-10.0^{\circ}$ to $0.0^{\circ} \mathrm{d}$ Dec.30
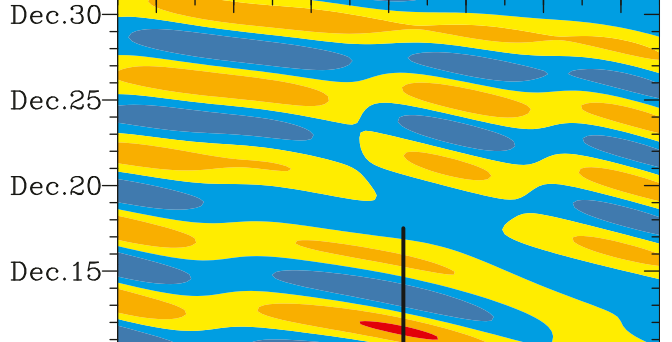

Dec. 10
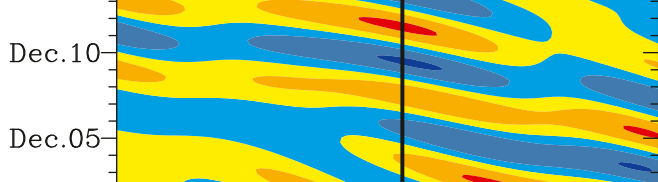

Nov. 30

Nov.25
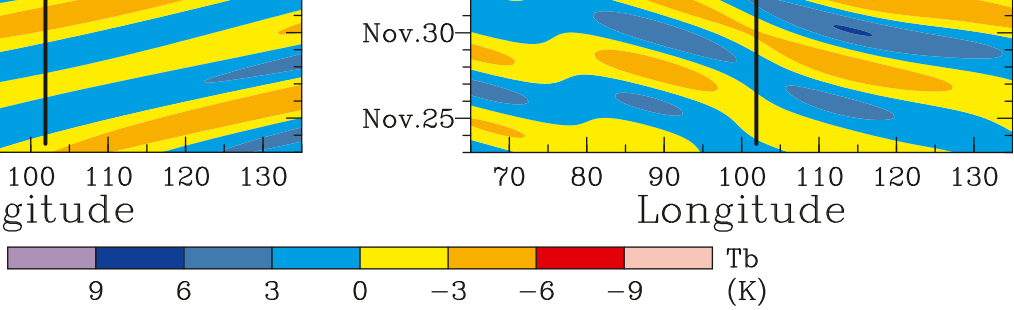

FIG. 3. (a) Time-longitude diagram of the MJO-filtered globally merged infrared brightness temperature $T_{b}$ anomalies, averaged from $0^{\circ}$ to $10^{\circ} \mathrm{S}$ for $23 \mathrm{Nov}-31 \mathrm{Dec} 2015$. The thick vertical line represents the observational period and the location of the Mirai. (b) As in (a), but for ERW-filtered $T_{b}$ anomalies. (c) As in (a), but for KWfiltered $T_{b}$ anomalies. (d) As in (a), but for MRGW-filtered $T_{b}$ anomalies. In all panels, the cold and warm colors denote positive and negative anomalies, respectively.

suppressed around 5 December. Notably, the $10-\mathrm{dB} Z$ stratiform echo areas after the peak MJO date became much larger than they were before. This low-frequency variation is also evident in the time series of the $30-\mathrm{dBZ}$ stratiform echo areas and stratiform volumetric rainfall (Figs. $6 \mathrm{~d}, \mathrm{j}$ ), but more obscure in the time series of the convective areas and volumetric rainfall (Figs. 6a,c,i).

Finally, it was interesting to find that echo-top heights exhibited a low-frequency variation with its phase approximately opposite to that of echo areas and volumetric rainfall. Figures $6 \mathrm{e}-\mathrm{g}$ show that the $10-$ and $30-\mathrm{dB} Z$ convective echo-top heights and $10-\mathrm{dB} Z$ stratiform echo-top heights peaked around 7 December, that is, 6 days before the peak MJO date, which was close to the results of DePasquale et al. (2014). In contrast, the echo-top heights shown in Figs. 6e-g tended to be lower around 30 November and after 13 December. 


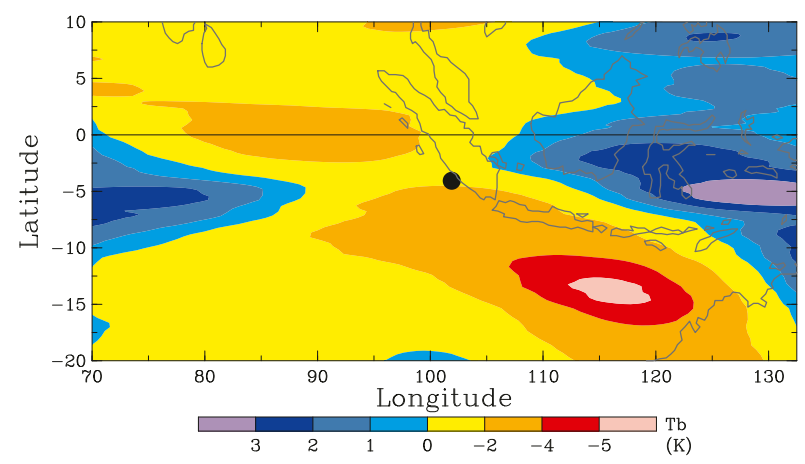

FIG. 4. Horizontal distribution of the MJO-filtered globally merged infrared brightness temperature $T_{b}$ anomalies, averaged from 1200 UTC 23 Nov to 1200 UTC 17 Dec 2015, when a stationary observation was conducted on the Research Vessel Mirai. The location of the Mirai is shown by a filled circle. The cold and warm colors denote positive and negative anomalies, respectively.

Figure 7 shows the time series of the standardized (zero mean and unit variance) radar-derived variables of the echo areas, echo-top heights, and volumetric rainfall, after a 2-day running mean has been applied. Time series of the filtered $T_{b}$ anomalies as shown in Fig. 5 are superimposed in Fig. 7. Figure 7 suggests that the previously shown high- and lowfrequency variations of the radar-derived variables evolved in accordance with the passages of KWs or MRGWs and the MJO or ERWs, respectively, which were similar to the rainfall variations modulated by the MJO and CCEWs in tropical regions (Powell and Houze 2013; Zuluaga and Houze 2013; Schlueter et al. 2019). Furthermore, the variation amplitudes of the convective and stratiform echoes differed around the peak MJO date. The maximum values of the $10-$ and $30-\mathrm{dB} Z$ stratiform echo areas and stratiform volumetric rainfall occurring 2 days after the peak MJO date were at least twice as high as their convective counterparts (Figs. 7a-d, i, and j), which is consistent with the dominant variations of stratiform precipitation areas and rainfall within an MJO (Lin et al. 2004; Morita et al. 2006; Barnes and Houze 2013; Powell and Houze 2013). In contrast, the magnitudes of most of the convective echo-top heights from 3 December to the end of the stationary observation period were higher than those of the stratiform echo-top heights (Figs. 7e-h), indicating larger variation in convective echo-top heights than in stratiform ones during the active phase of the MJO event.

Time series of the MCS and sub-MCS populations are shown in Figs. $8 \mathrm{a}$ and $8 \mathrm{~b}$. The sub-MCS population was almost always larger than the MCS population, indicating that sub-MCSs were the dominant organizational mode of convective activity during the observational period of the Mirai. This result is consistent with observations from the DYNAMO shipborne radar (Xu and Rutledge 2015). The MCS and sub-MCS populations also varied on a time scale of 3-5 days. Notably, the phase of high-frequency variation in the MCS population was approximately opposite to that of the sub-MCS population; the MCS population tended to be large when the sub-MCS occurrence decreased and vice versa. In addition, the sub-MCS population exhibited low-frequency variation more prominently than the MCS population (Figs. 8a,b). It was noted that the variation
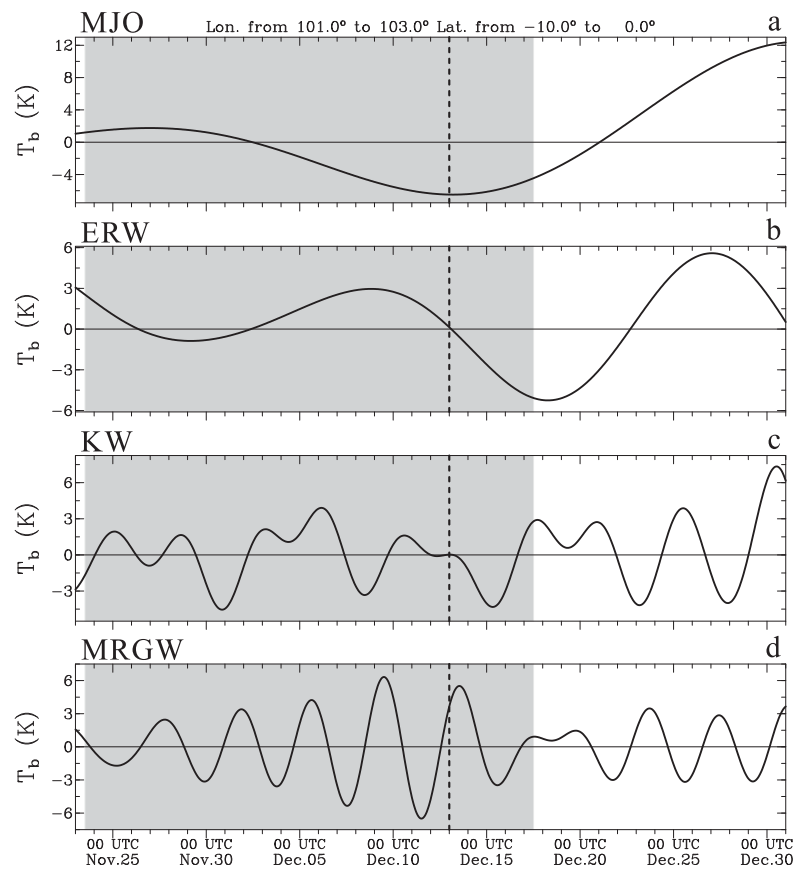

FIG. 5. (a) Time series of the MJO-filtered globally merged infrared brightness temperature $T_{b}$ anomalies, averaged from $101^{\circ}-103^{\circ} \mathrm{E}$ to $0^{\circ}-10^{\circ} \mathrm{S}$ for $23 \mathrm{Nov}-31 \mathrm{Dec} 2015$. The vertical dashed line indicates the peak MJO date. The period of the stationary observation of the Mirai is shaded in gray. (b) As in (a), but for ERW-filtered $T_{b}$ anomalies. (c) As in (a), but for KW-filtered $T_{b}$ anomalies. (d) As in (a), but for MRGW-filtered $T_{b}$ anomalies.

amplitude of the sub-MCS population around the peak MJO date was larger than that of the MCS population (Figs. 8c,d).

Figure 9 shows the probability distribution functions (PDFs) of echo-top heights. There were major differences in the vertical extent of the 10-dBZ echo-top heights between MCSs and sub-MCSs and between convective and stratiform precipitation (Figs. 9a,b). The PDFs of the 10-dBZ echo-top heights indicated the emergence of deeper convective and stratiform precipitation in MCSs than in sub-MCSs, which is consistent with the observational results obtained during DYNAMO (Rowe and Houze 2014; Xu and Rutledge 2015). For the echoes of the MCSs, it was noted that the PDF of the $10-\mathrm{dB} Z$ convective echo-top heights peaked at $11 \mathrm{~km}$, whereas that of the $10-\mathrm{dBZ}$ stratiform echo-top heights peaked at only $8 \mathrm{~km}$. The significantly lower modal height of the stratiform echoes implies that, in addition to old convection, a broader mesoscale ascent in the midtroposphere also played an important role in the formation of stratiform precipitation (Houze 2004). The marked difference between the convective and stratiform echo-top heights of the MCSs in this study contrasts with the DYNAMO results of Rowe and Houze (2014), who observed that the convective and stratiform precipitation of MCSs exhibit similar modal heights in terms of $0-\mathrm{dB} Z$ echo-top heights.

\section{Relationships between radar-derived variables and large-scale disturbances}

To investigate the effects of the MJO, ERWs, KWs, and MRGWs passages on the variances of convective activities 
Convective
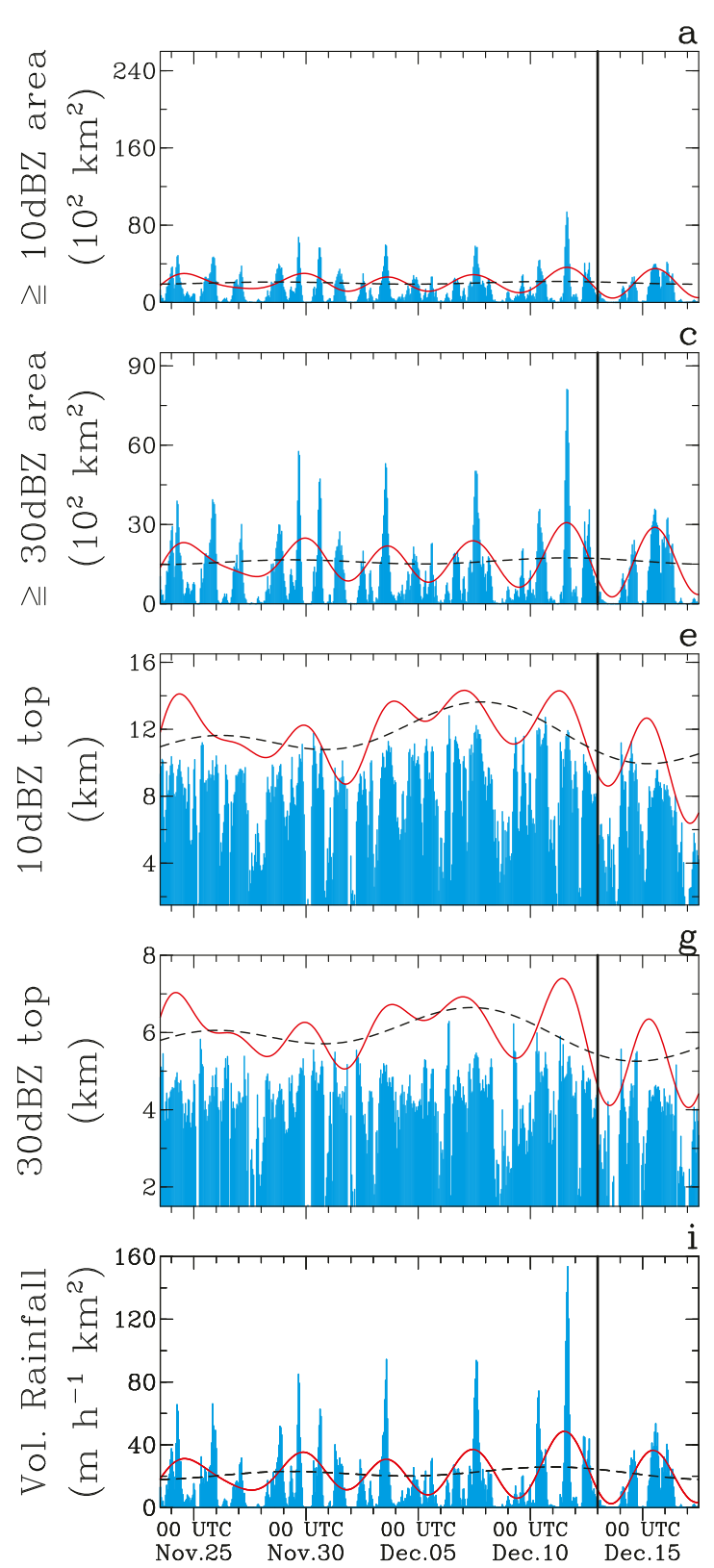

Stratiform

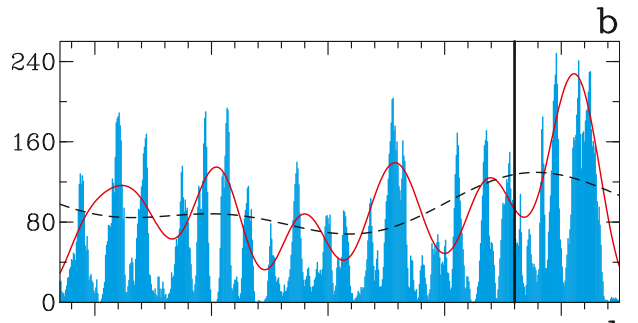

d
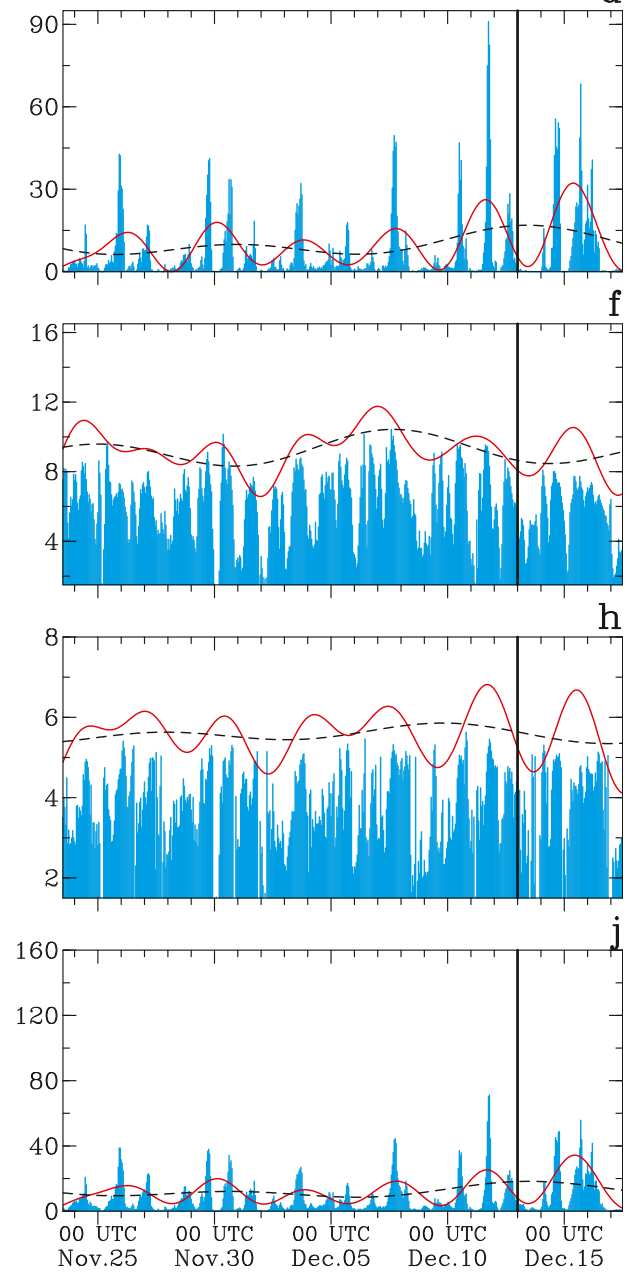

FIG. 6. Time series of the echo areas of $\geq 10 \mathrm{dBZ}$ at $2 \mathrm{~km}$ (cyan vertical bars) for (a) convective and (b) stratiform echoes over the radar domain. The results after applying fast Fourier transform (FFT) low-pass filters with cutoff periods of 3 and 9 days are shown by the red curves and black dashed curves, respectively. To enhance figure appearance, the filtered results are scaled by a factor of 0.65 . The black vertical line indicates the peak MJO date. (c),(d) As in (a) and (b), but for the echo areas of $\geq 30 \mathrm{dBZ}$ at $2 \mathrm{~km}$. (e),(f) As in (a) and (b), but for the 10-dBZ echo-top heights. (g),(h) As in (a) and (b), but for the 30-dBZ echo-top heights. (i),(j) As in (a) and (b), but for volumetric rainfall at $2 \mathrm{~km}$.

during the MJO event, each time series of the radar-derived variables shown in Figs. 6 and 8 was regressed against the MJO, ERW, KW, and MRGW indices (i.e., the time series of the filtered $T_{b}$ anomalies shown in Fig. 5). The sample number used in the regression analysis was 577. A correlation coefficient from an SLR analysis is statistically significant at the $99 \%$ level when its absolute value is greater than or equal to 0.11 . A negative correlation between the radar-derived variable and the index of an MJO event or a particular equatorial wave indicated that the radar-derived variable tended to be enhanced during the active phase but weakened during the suppressed phase of 
Convective
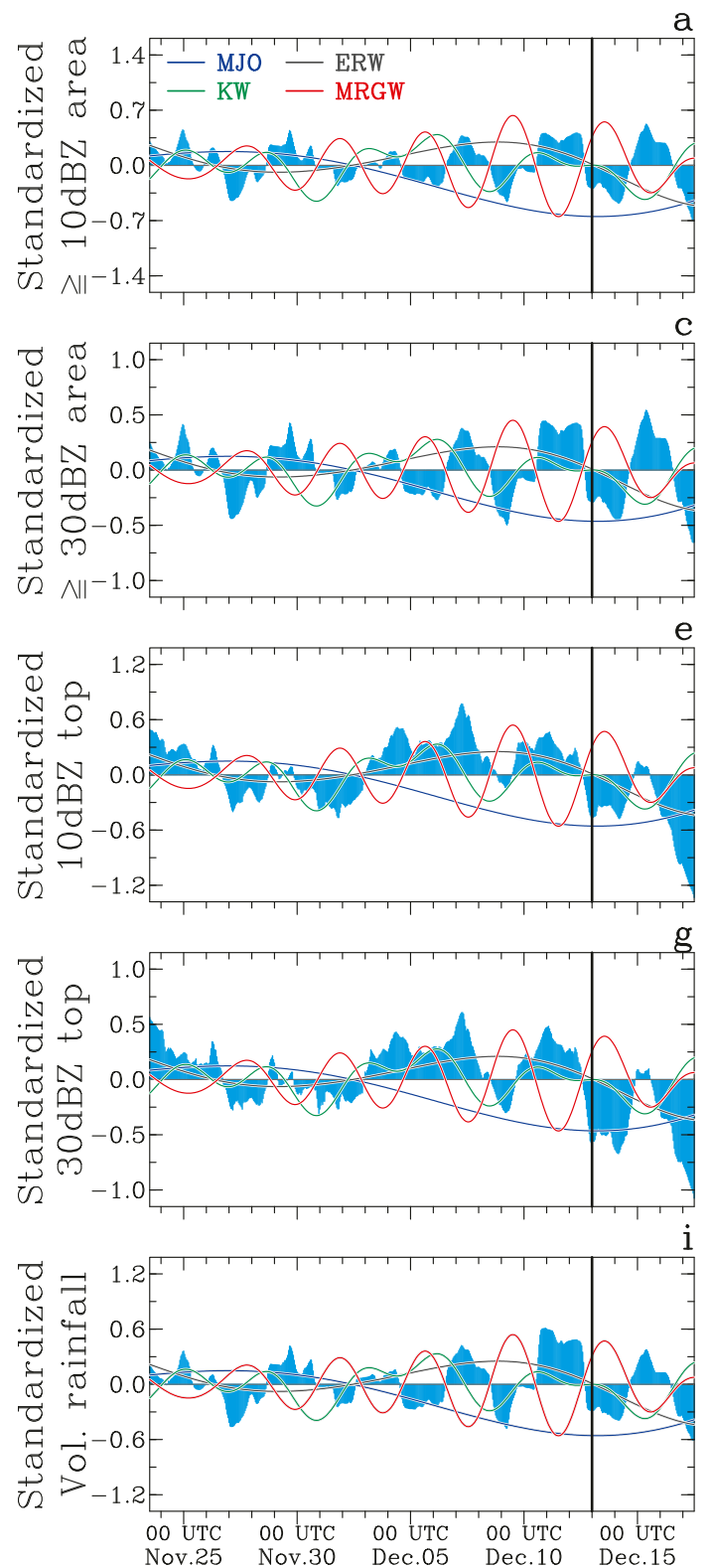

Stratiform

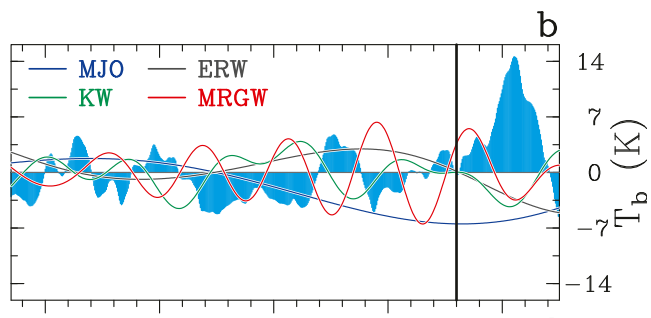

d

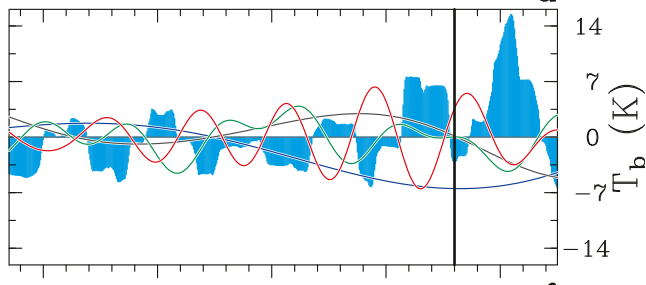

f

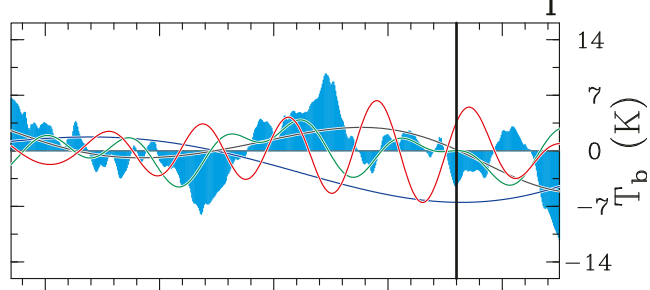

$\mathrm{h}$
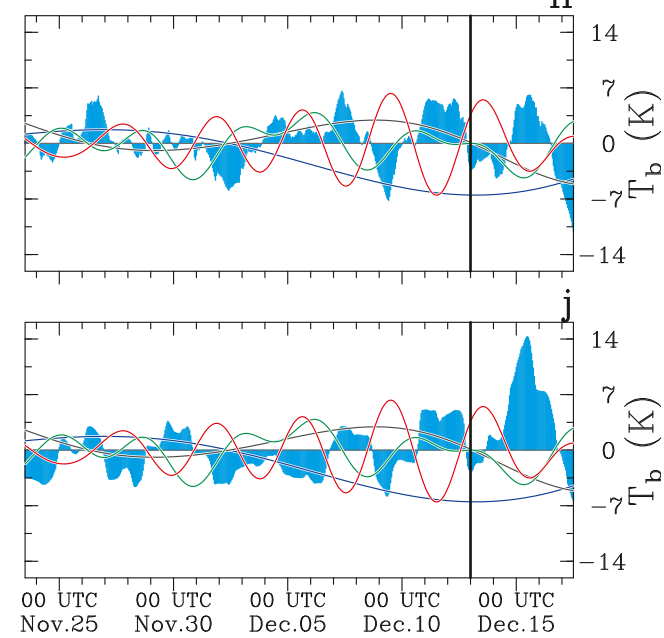

FIG. 7. Time series of the standardized echo areas of $\geq 10 \mathrm{dBZ}$ at $2 \mathrm{~km}$ (cyan shading) for (a) convective and (b) stratiform echoes over the radar domain. The standardization was designed for the period shown in the figure by removing the mean and by scaling to unit variance. A 2-day running mean was applied to each time series. Time series of filtered globally merged infrared brightness temperature anomalies averaged from $101^{\circ}-103^{\circ} \mathrm{E}$ to $0^{\circ}-10^{\circ} \mathrm{S}$ (curves) are superimposed. The black vertical line indicates the peak MJO date. (c),(d) As in (a) and (b), but for the standardized echo areas of $\geq 30 \mathrm{~dB} Z$ at $2 \mathrm{~km}$. (e),(f) As in (a) and (b), but for the standardized 10-dBZ echo-top heights. (g),(h) As in (a) and (b), but for the standardized 30-dBZ echo-top heights. (i),(j) As in (a) and (b), but for the standardized volumetric rainfall at $2 \mathrm{~km}$.

the MJO or equatorial wave event (and vice versa for a positive correlation).

The individual contributions of the MJO, ERW, KW, and MRGW indices to the squared multiple correlation coefficient $\left(R^{2}\right)$ from a standardized MLR analysis were used to estimate the relative influences of the large-scale disturbances on the variances of the radar-derived variables. Note that $R^{2}$ equals the sum of the individual contributions. The $R^{2}$ is statistically significant at the $99 \%$ level when its value is greater than or equal to 0.023 . As seen below, all the $R^{2}$ values derived in this 
MCSs
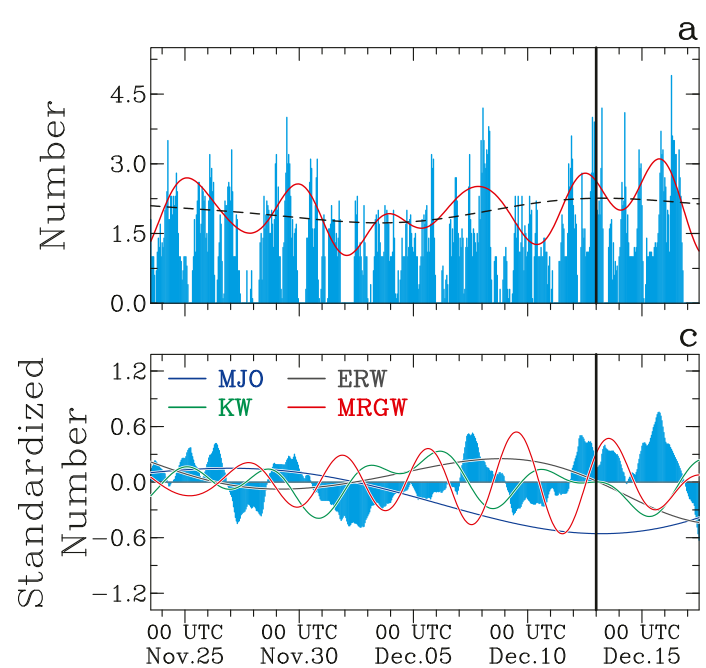

sub-MCSs
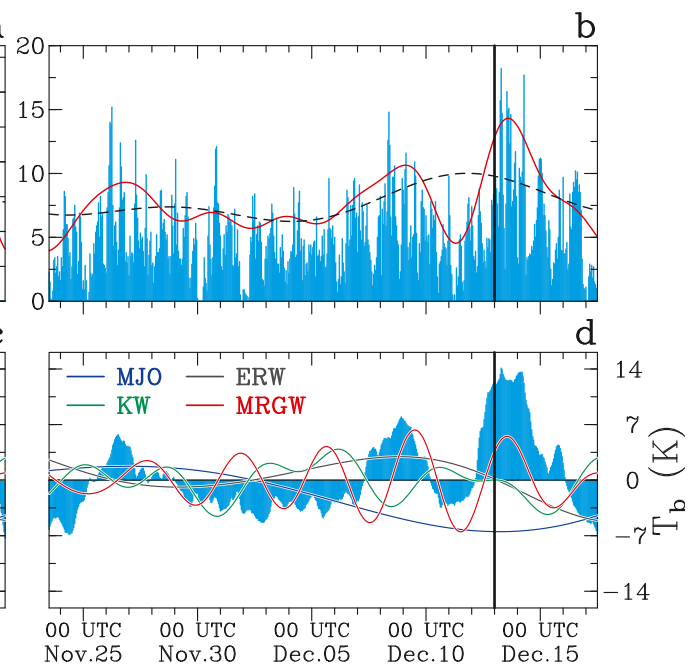

FIG. 8. Time series of the population (cyan vertical bars) of (a) MCSs and (b) sub-MCSs over the radar domain. The results after applying fast Fourier transform (FFT) low-pass filters with cutoff periods of 3 and 9 days are shown by the red curves and black dashed curves, respectively. To enhance figure appearance, the filtered results are scaled by a factor of 0.65. Time series of the standardized population (cyan shading) of (c) MCSs and (d) sub-MCSs over the radar domain. The standardization was designed for the period shown in the figure by removing the mean and by scaling to unit variance. A 2-day running mean was applied to each time series of the standardized population. Time series of filtered globally merged infrared brightness temperature anomalies averaged from $101^{\circ}-103^{\circ} \mathrm{E}$ to $0^{\circ}-10^{\circ} \mathrm{S}$ (curves) are superimposed. The black vertical line in each panel indicates the peak MJO date.

study were larger than this value, and were therefore statistically significant at the $99 \%$ level. It should be pointed out that the interactions between different large-scale disturbances cannot be taken into account using an MLR analysis. Consequently, the relative influences of the MJO, ERWs, KWs, and MRGWs described in this study should be understood as being independent of their possible interactions.
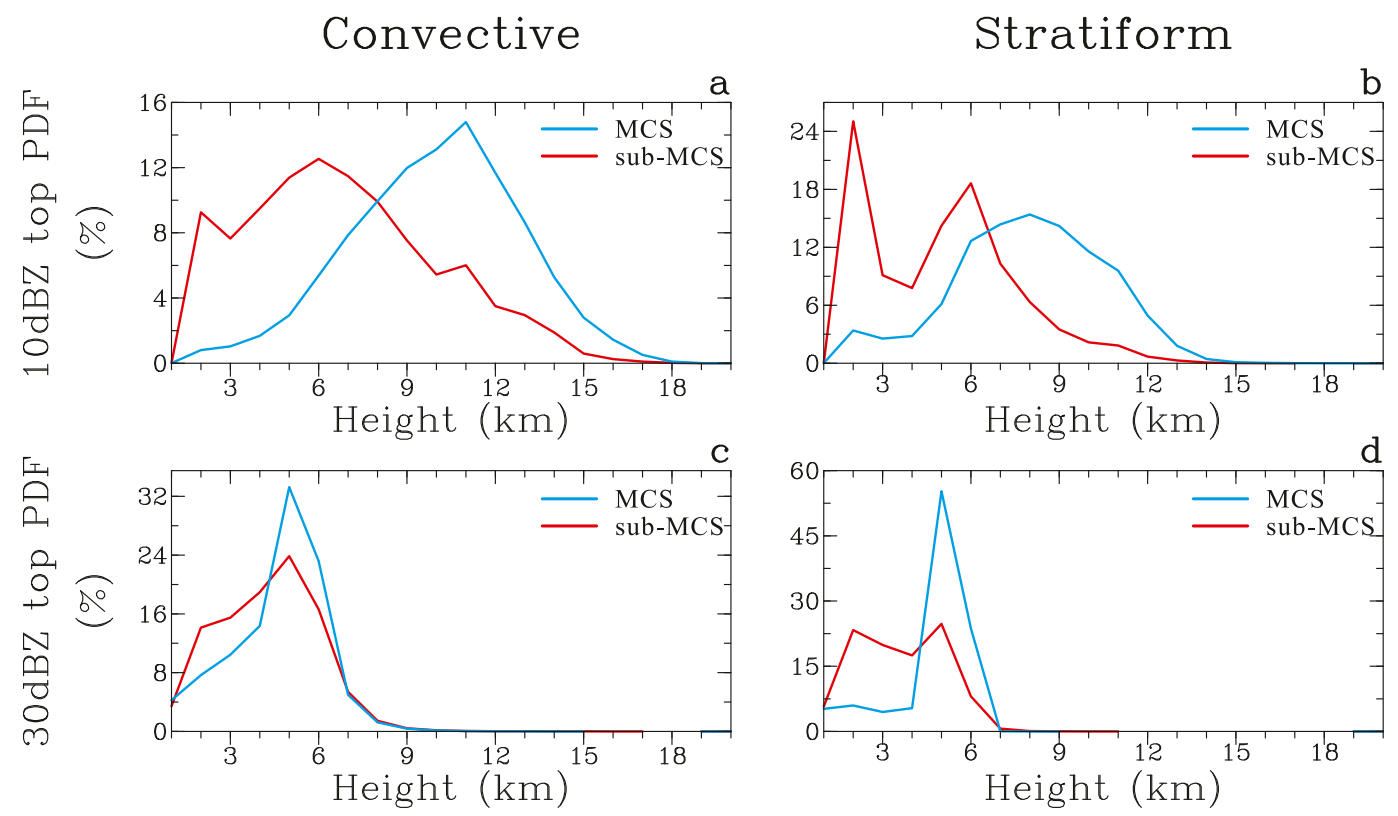

FIG. 9. Probability distribution functions (PDFs) of the 10-dBZ echo-top heights of MCSs (cyan curves) and sub-MCSs (red curves) for (a) convective and (b) stratiform echoes over the radar domain. The PDFs were derived at 1-km intervals. (c),(d) As in (a) and (b), but for the 30-dBZ echo-top heights. 


\section{a. Echo areas at $2 \mathrm{~km}$}

The regressed results of the $10-\mathrm{dB} Z$ convective echo areas based on an SLR analysis are shown in Fig. 10a. The correlation coefficient of the MRGW index $(-0.31)$ was negative and was the only one that was statistically significant (at the $99 \%$ level, same hereafter), indicating that convective echo areas tend to increase or diminish during the active or suppressed phases of MRGWs.

Figure $10 \mathrm{~b}$ shows the regressed results of the $10-\mathrm{dBZ}$ convective echo areas based on an MLR analysis. The $R^{2}$ and the contribution of each index to $R^{2}$ are shown at the top of Fig. 10b. The MLR result had an $R^{2}$ value of 0.103 , indicating that $10.3 \%$ of the observed variance of $10-\mathrm{dBZ}$ convective echo areas can be accounted for by the variances in the MJO, ERWs, KWs, and MRGWs. Notably, the percentage contribution of the MRGW index $(9.5 \%)$ was very close to the value of $R^{2}$. In addition, there were small contributions from the KW $(0.5 \%)$ and ERW $(0.3 \%)$ indices, but none from the MJO index.

The regressed results of the $30-\mathrm{dB} Z$ convective echo areas (Fig. 11) were similar to those of the $10-\mathrm{dB} Z$ convective echo areas (Fig. 10). The correlation coefficient of the MRGW index $(-0.33)$ was also negative and the only one that was statistically significant (Fig. 11a). The contribution of the MRGW index $(10.7 \%)$ to the observed variance was also very close to the value of $R^{2}(11.4 \%)$ (Fig. 11b). There were also small contributions from the KW (0.5\%) and ERW (0.2\%) indices, but no contribution from the MJO index.

Figures 10 and 11 indicate that the MRGWs exerted the predominant modulation, whereas the MJO event had little influence on the variances of either the 10 - or the $30-\mathrm{dBZ}$ convective echo areas in the lower troposphere. Comparisons of Fig. 10b with Fig. 10a and Fig. 11b with Fig. 11a reveal that the MRGWs strongly enhanced and interrupted the horizontal extent of the convective echoes several times during the passage of the MJO event.

The regressed results of the $10-\mathrm{dB} Z$ stratiform echo areas, based on an SLR analysis against each of the MJO, ERW, KW, and MRGW indices, are shown in Fig. 12a. All the indices exhibited statistically significant and negative correlations with $10-\mathrm{dB} Z$ stratiform echo areas, indicating that the stratiform echo areas tended to increase during the active phase but diminish during the suppressed phase of the MJO or any of the equatorial waves. The larger-scale disturbances contributed up to $18.9 \%$ of the observed variance in the $10-\mathrm{dB} Z$ stratiform echo areas (Fig. 12b), larger than their contribution to the observed variance in the $10-\mathrm{dB} Z$ convective echo areas $(10.3 \%$, Fig. $10 \mathrm{~b})$ by a factor of 1.8 . This fact indicates that the large-scale disturbances in combination can induce larger variance in stratiform echo areas than in convective echo areas. The percentage contributions of the MJO, ERW, KW, and MRGW indices to the $10-\mathrm{dBZ}$ stratiform echo area variance were $2 \%, 2 \%, 8.8 \%$, and $6.1 \%$, respectively (Fig. 12b), indicating that each of these large-scale disturbances exerts a certain degree of influence on the variance of $10-\mathrm{dB} Z$ stratiform echo areas. The KW and MRGW indices contributed more than the MJO and ERW indices to the $10-\mathrm{dBZ}$
Convective area of $\geqq 10 \mathrm{dBZ}$
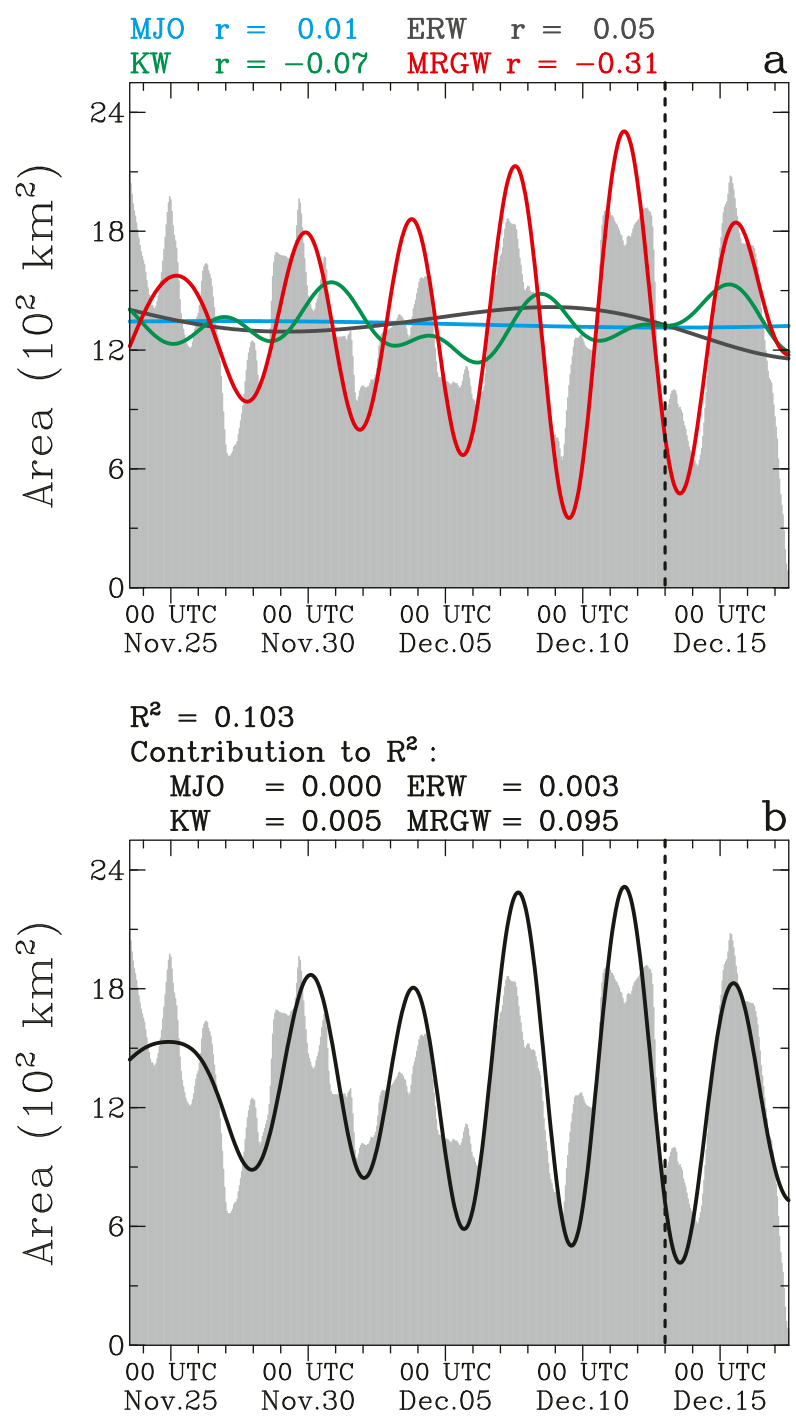

FIG. 10. (a) Time series of the regressed results for the convective echo areas of $\geq 10 \mathrm{dBZ}$ at $2 \mathrm{~km}$, based on an SLR analysis against the MJO index (cyan curve), the ERW index (dark gray curve), the $\mathrm{KW}$ index (green curve), and the MRGW index (red curve). The correlation coefficient ( $r$ ) for each index is shown at the top. (b) Time series of the regressed result for the convective echo areas of $\geq 10 \mathrm{dBZ}$ at $2 \mathrm{~km}$, based on an MLR analysis against all indices (black curve). The squared multiple correlation coefficient $\left(R^{2}\right)$ and the contribution of each index to $R^{2}$ are shown at the top. In both (a) and (b), the radar-observed $10-\mathrm{dB} Z$ convective echo areas after applying a 2-day running mean are shaded in gray. The vertical dashed line indicates the peak MJO date.

stratiform echo area variance. Notably, the KW index made the strongest contribution to $R^{2}$, indicating that KWs exert the strongest effect on the variance of $10-\mathrm{dB} Z$ stratiform echo areas in the lower troposphere.

Figure 13 shows the regressed results of the $30-\mathrm{dBZ}$ stratiform echo areas. Similar to the $10-\mathrm{dB} Z$ stratiform echo areas 


\section{Convective area of $\geqq 30 \mathrm{dBZ}$}
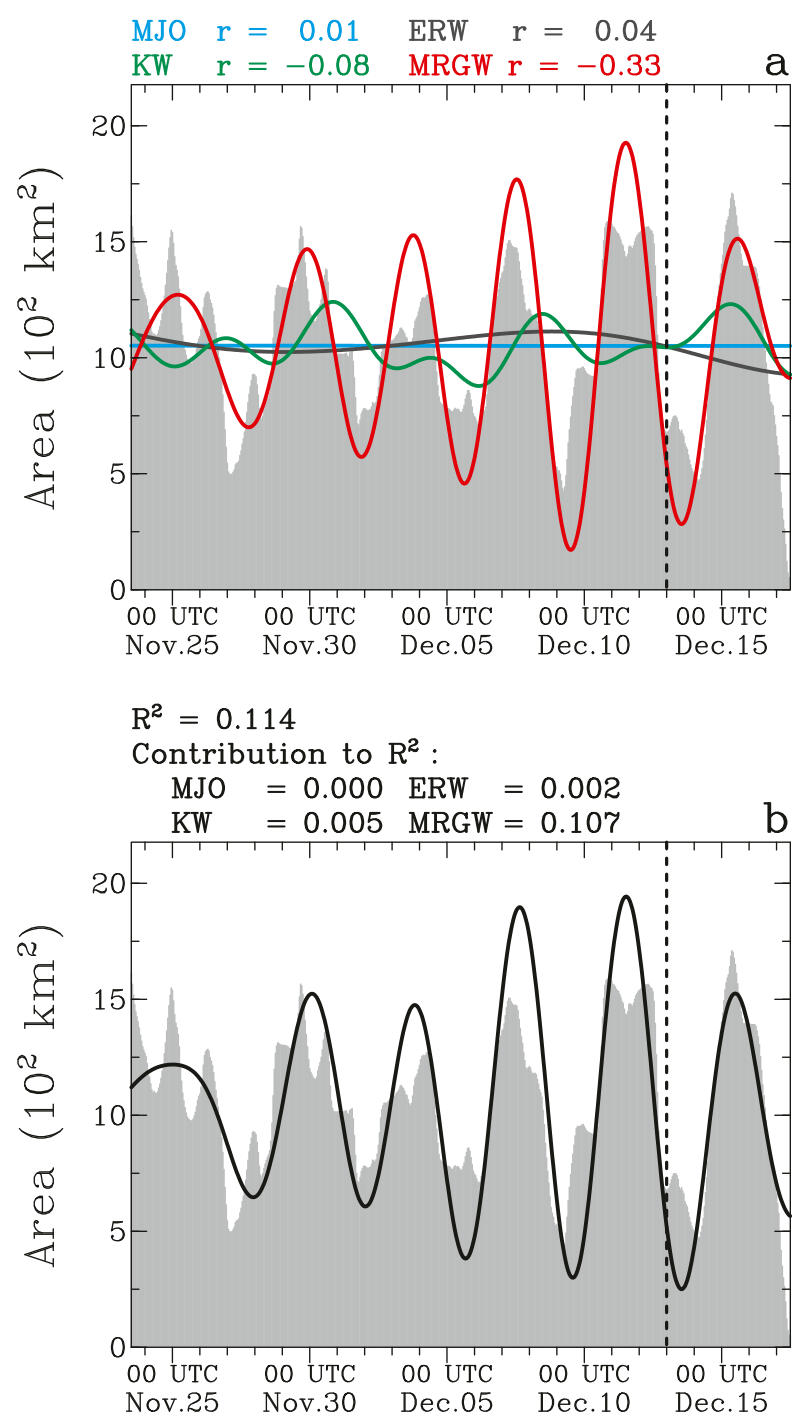

FIG. 11. As in Fig. 10, but for the convective echo areas of $\geq 30 \mathrm{dBZ}$ at $2 \mathrm{~km}$.

(Fig. 12a), all indices also exhibited negative correlations with the $30-\mathrm{dB} Z$ stratiform echo areas, but the correlation coefficient of the ERW index (-0.10) was slightly insignificant (Fig. 13a). The large-scale disturbances accounted for $14.7 \%$ of the observed variance of the $30-\mathrm{dB} Z$ stratiform echo areas (Fig. 13b), approximately 1.3 times larger than their contribution to the $30-\mathrm{dB} Z$ convective echo area variance $(11.4 \%$, Fig. 11b). This indicates that, in combination, the large-scale disturbances can also induce more variance in $30-\mathrm{dB} Z$ stratiform echo areas than in $30-\mathrm{dB} Z$ convective echo areas. Notably, although the KW (3.3\%) and MRGW (9.1\%) indices were still the major contributors, the contribution of the MRGW index to the $30-\mathrm{dB} Z$ stratiform echo area variance was nearly 3 times as high as that of the KW index. This fact indicates that, in contrast to $10-\mathrm{dB} Z$ stratiform echo areas, 30-dBZ
Stratiform area of $\geqq 10 \mathrm{dBZ}$
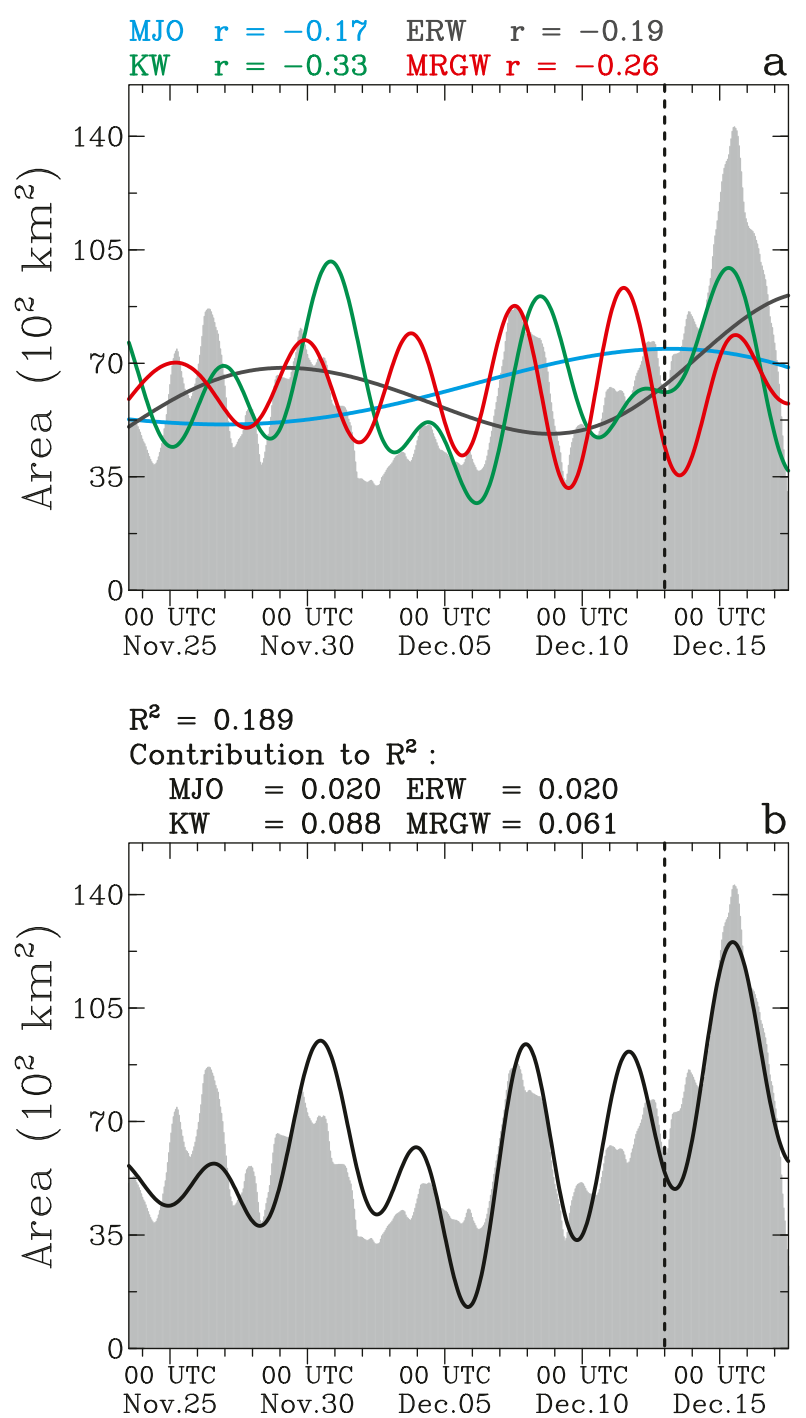

FIG. 12. As in Fig. 10, but for the stratiform echo areas of $\geq 10 \mathrm{dBZ}$ at $2 \mathrm{~km}$.

stratiform echo area variance in the lower troposphere is more strongly influenced by MRGWs than by KWs.

As shown in Figs. 12a and 13a, the KWs and MRGWs were largely responsible for the high-frequency variations, while the MJO and ERWs contributed to the low-frequency variations of both the 10- and 30-dBZ stratiform echo areas in the lower troposphere. Comparing Fig. 12b with Fig. 12a and Fig. 13b with Fig. 13a makes it evident that the superposition of the active phases of the large-scale disturbances facilitates the horizontal extension of stratiform echoes, whereas the superposition of their suppressed phases limits the stratiform echo areas. This is particularly true for the extensive development of stratiform echoes around 15-16 December, when the active phases of the MJO, ERW, KW, and MRGW events overlapped (Fig. 5). This explains why the stratiform echoes 
Stratiform area of $\geqq 30 \mathrm{dBZ}$
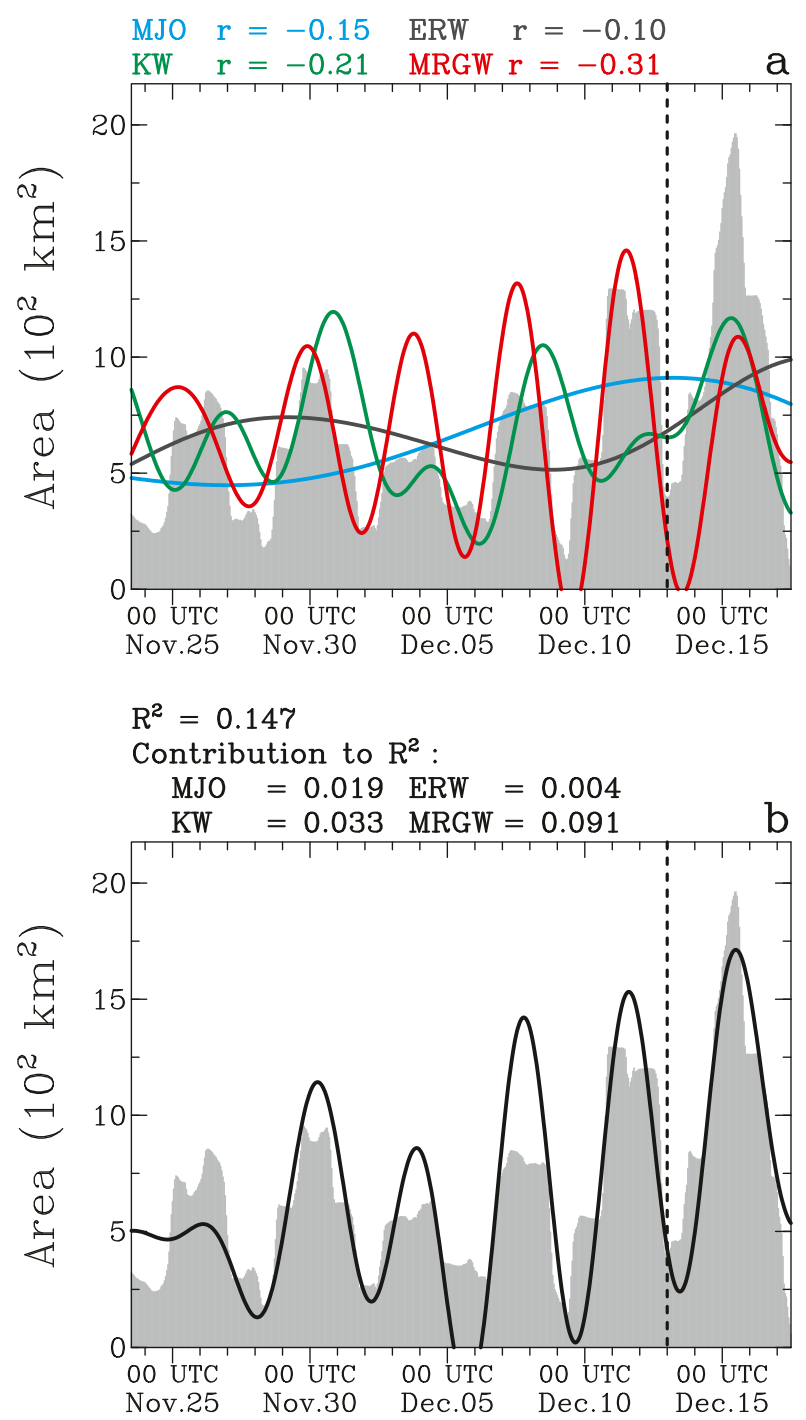

FIG. 13. As in Fig. 10, but for the stratiform echo areas of $\geq 30 \mathrm{dBZ}$ at $2 \mathrm{~km}$.

in the lower troposphere developed extensively after the peak MJO date.

\section{b. Echo-top heights}

The regressed results of the $10-\mathrm{dB} Z$ convective echo-top heights are shown in Fig. 14. The MRGW index had a significantly negative correlation coefficient $(-0.23)$ (Fig. 14a), indicating that the active phases of MRGWs also facilitate the vertical development of convective echoes. Interestingly, the correlation coefficient of the ERW index (0.30) was positive and statistically significant, suggesting that instead of the active phases, the suppressed phases of ERWs tend to promote the vertical extension of convective echoes. Notably, the ERW index was more strongly correlated with the $10-\mathrm{dB} Z$ convective echo-top heights than the MRGW index. Figure 14b indicates that the percentage contribution of the large-scale disturbances to the variance of convective echo-top heights was $14.3 \%$, with the MRGW (5.1\%) and ERW (9.1\%) indices being the two major contributors. In contrast, no contribution from the MJO index and only a small contribution from the KW index $(0.1 \%)$ was observed. The regressed results indicate that the variance of the $10-\mathrm{dBZ}$ convective echo-top heights is largely influenced by both MRGWs and ERWs, with the latter having the strongest impact.

Figure 15 shows the regressed results of the $30-\mathrm{dBZ}$ convective echo-top heights. Similar to the $10-\mathrm{dB} Z$ convective echo-top heights (Fig. 14), the MRGW and ERW indices were also negatively and positively correlated with the $30-\mathrm{dB} Z$ convective echo-top heights, respectively, with only their correlation coefficients $(-0.25$ and 0.23 , respectively) being statistically significant (Fig. 15a). In addition, the $R^{2}(11.8 \%)$ of the $30-\mathrm{dBZ}$ convective echo-top heights was also largely contributed by the MRGW (6.1\%) and ERW (5.2\%) indices (Fig. 15b).

As shown in Figs. 14a and 15a, MRGWs and ERWs are largely responsible for the high- and low-frequency variations of convective echo-top heights, respectively. Comparisons of Fig. 14b with Fig. 14a and Fig. 15b with Fig. 15a reveal that, in addition to MRGWs, ERWs greatly promoted the vertical development of both the 10- and 30-dBZ convective echo-top heights before the peak MJO date around 7 December, when the active phases of the MRGWs were superimposed by the suppressed phase of the ERW (Figs. 5b,d). ERW-mediated suppression of the vertical extension of the convective echoes was also evident between 26 November and 2 December and after the peak MJO date, i.e., 13 December, when the active phases of the ERWs passed by (Fig. 5b). In particular, it appears that the significant reduction in the vertical extension of the convective echoes after the peak MJO date was largely induced by an ERW during its active phase. It was noted that ERWs contributed little to the variances of convective echo areas at $2 \mathrm{~km}$ (Figs. 10-11). Therefore, the strong modulation of ERWs on the variances of both the 10- and $30-\mathrm{dBZ}$ convective echo-top heights implies that upper-level forcing of ERWs can greatly impact the vertical development of convection within $\mathrm{MJO}$ events.

Figure 16 shows the regressed results of the $10-\mathrm{dB} Z$ stratiform echo-top heights. The correlation coefficients of the MRGW (-0.2) and ERW (0.19) indices were statistically significant (Fig. 16a). Similar to the 10-dBZ convective echo-top heights (Figs. 14a), the MRGW and ERW indices were also negatively and positively correlated with the $10-\mathrm{dBZ}$ stratiform echo-top heights, respectively. Notably, the correlation of the ERW index against the $10-\mathrm{dB} Z$ stratiform echo-top heights was weaker than that against the $10-\mathrm{dBZ}$ convective echo-top heights (Figs. 14a and 16a). Figure 16b indicates that $7.6 \%$ of the observed variance of the $10-\mathrm{dB} Z$ stratiform echo-top heights can be accounted for by the variances in MRGWs and ERWs. In contrast, no contributions from the MJO and $\mathrm{KW}$ indices were observed. Similar to the 10-dBZ convective echo-top heights (Fig. 14a), MRGWs and ERWs were also largely responsible for the high- and low-frequency variations of the $10-\mathrm{dB} Z$ stratiform echo-top heights, respectively (Fig. 16a). 


\section{Convective 10dBZ top}
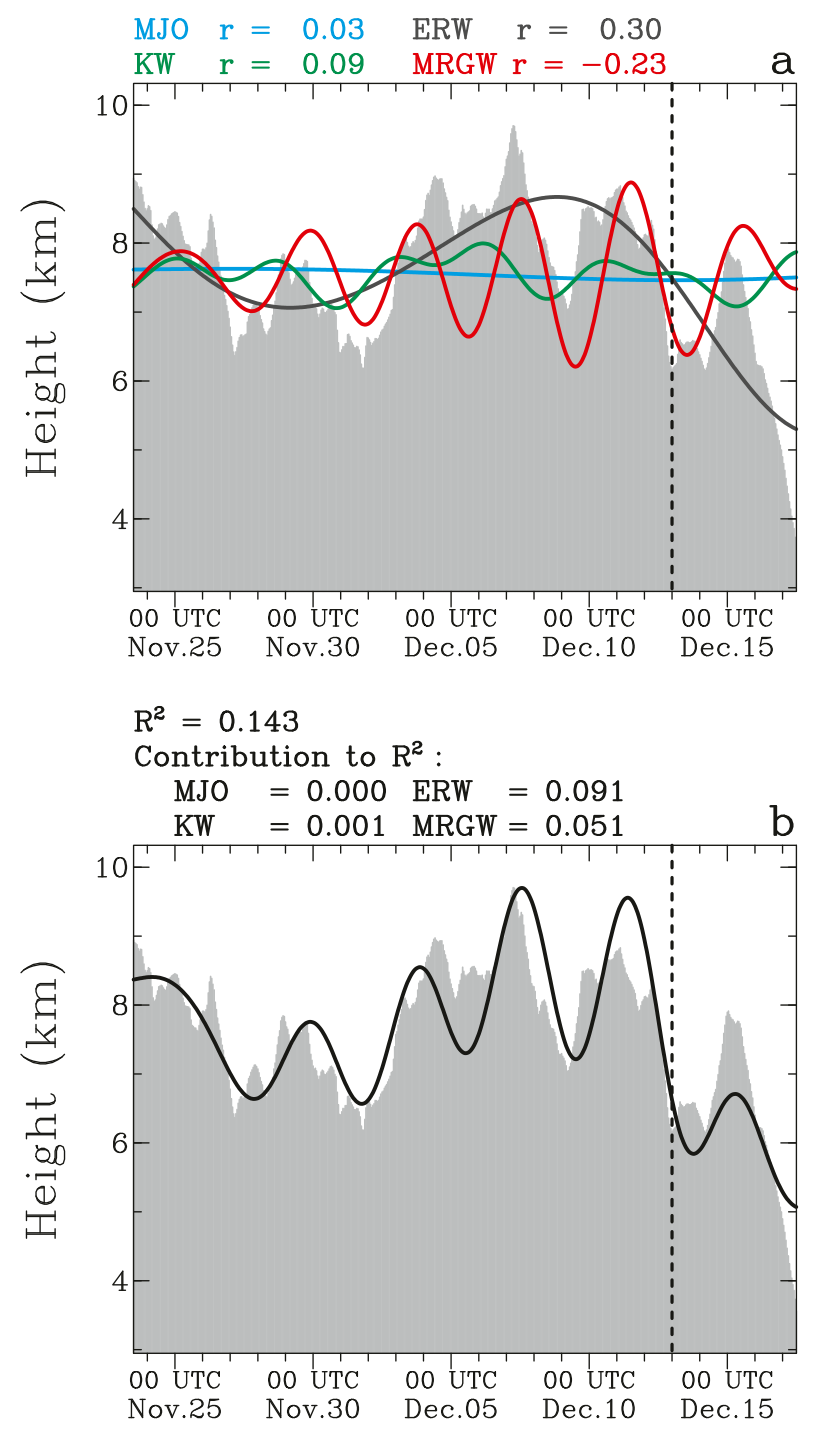

FIG. 14. (a) Time series of the regressed results for the $10-\mathrm{dBZ}$ convective echo-top heights, based on an SLR analysis against the MJO index (cyan curve), the ERW index (dark gray curve), the KW index (green curve), and the MRGW index (red curve). The correlation coefficient $(r)$ for each index is shown at the top. (b) Time series of the regressed result for the $10-\mathrm{dB} Z$ convective echo-top heights, based on an MLR analysis against all indices (black curve). The squared multiple correlation coefficient $\left(R^{2}\right)$ and the contribution of each index to $R^{2}$ are shown at the top. In both (a) and (b), the radar-observed 10-dBZ convective echo-top heights after applying a 2-day running mean are shaded in gray. The vertical dashed line indicates the peak MJO date.

On comparing Fig. 16b with Fig. 14b, we observed that the contribution of the large-scale disturbances to the variance of the $10-\mathrm{dB} Z$ stratiform echo-top heights was nearly half that of the $10-\mathrm{dB} Z$ convective echo-top heights. This result was mainly caused by the reduction in the contribution of ERWs to the
Convective 30dBZ top
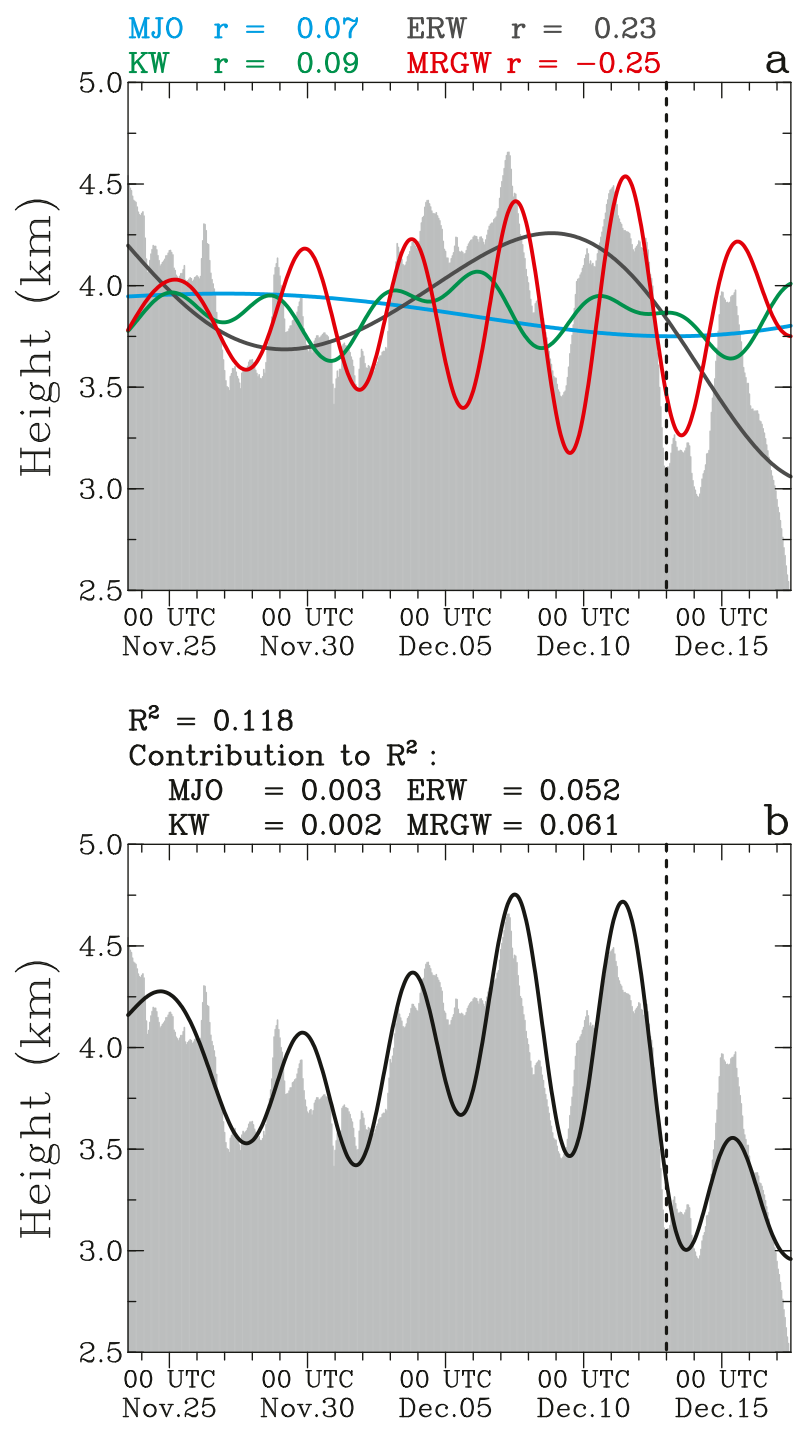

FIG. 15. As in Fig. 14, but for the 30-dBZ convective echo-top heights.

variance of the $10-\mathrm{dB} Z$ stratiform echo-top heights. It appears that the influence of ERWs on the variance of the stratiform echo-top heights was weaker than that on the variance of the convective echo-top heights.

The regressed results of the $30-\mathrm{dB} Z$ stratiform echo-top heights are shown in Fig. 17. Compared with $10-\mathrm{dB} Z$ stratiform echo-top heights (Fig. 16), the correlation coefficient of the ERW index (0.05, Fig. 17a) and its contribution $(0.3 \%$, Fig. 17b) were significantly reduced. This result further illustrates the weak influence of ERWs on the variance of stratiform echo-top heights. However, the correlation with the MRGW index was similar to that of the $10-\mathrm{dB} Z$ stratiform echo-top heights, with its contribution $(4.7 \%)$ to the $30-\mathrm{dBZ}$ stratiform echo-top height variance close to the value of $R^{2}(5.5 \%)$. 


\section{Stratiform 10dBZ top}
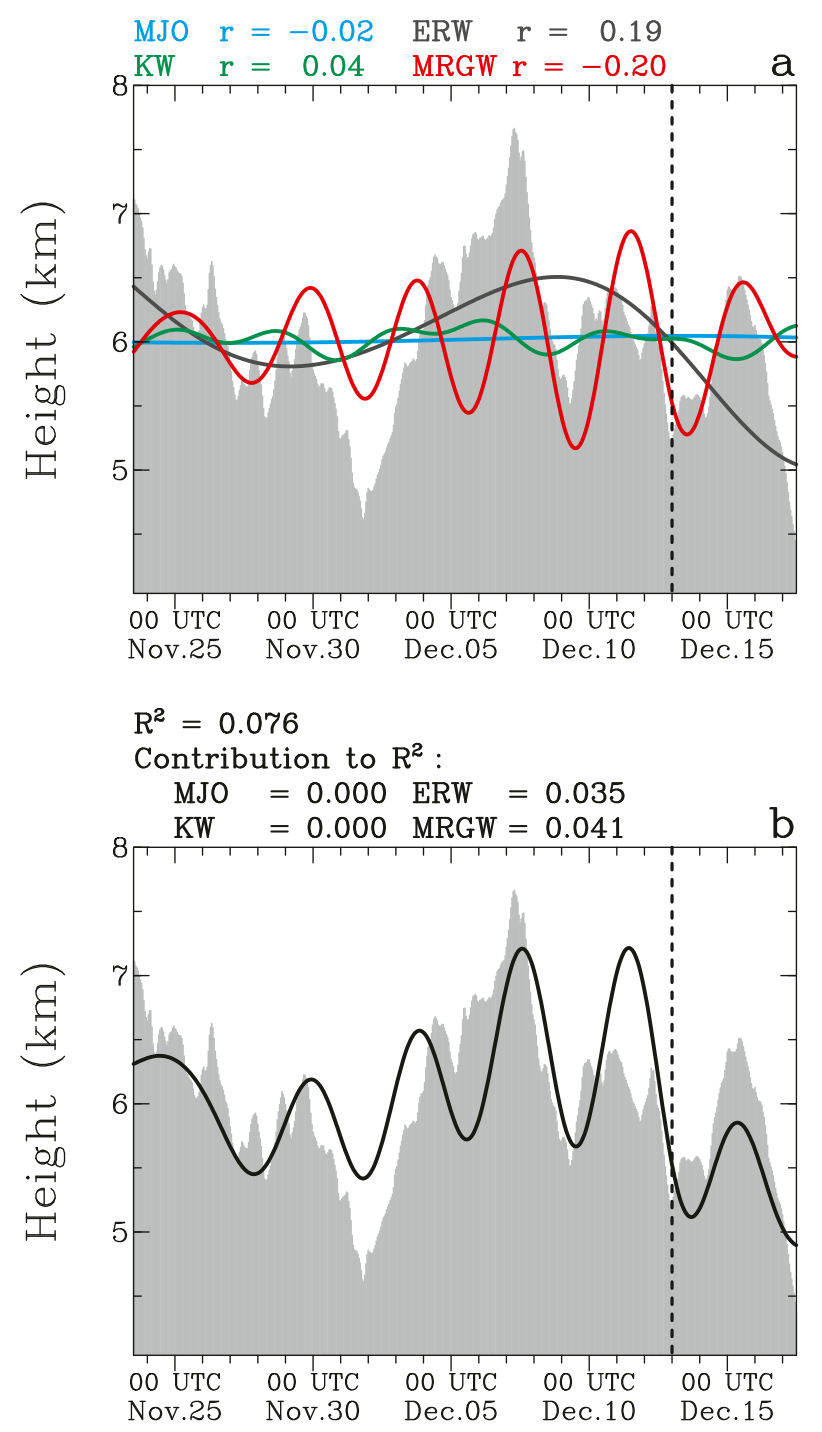

FIG. 16. As in Fig. 14, but for the 10-dBZ stratiform echo-top heights.

As shown in Fig. 17, accompanying the significant reduction in the contribution of ERWs, the low-frequency variation also became more obscure in the $30-\mathrm{dB} Z$ stratiform echo-top heights. Instead, the MRGWs exerted the predominant modulation on the high-frequency variation of the $30-\mathrm{dBZ}$ stratiform echo-top heights.

\section{c. Volumetric rainfall}

The regressed results of the convective volumetric rainfall are shown in Fig. 18. Similar to the convective echo areas (Figs. 10a and 11a), the correlation coefficient of only the MRGW index $(-0.34)$ was statistically significant (Fig. 18a). The large-scale disturbances accounted for $11.9 \%$ of the variance of the convective volumetric rainfall (Fig. 18b), with the contributions of the MJO, ERW, KW, and MRGW indices

\section{Stratiform 30dBZ top}
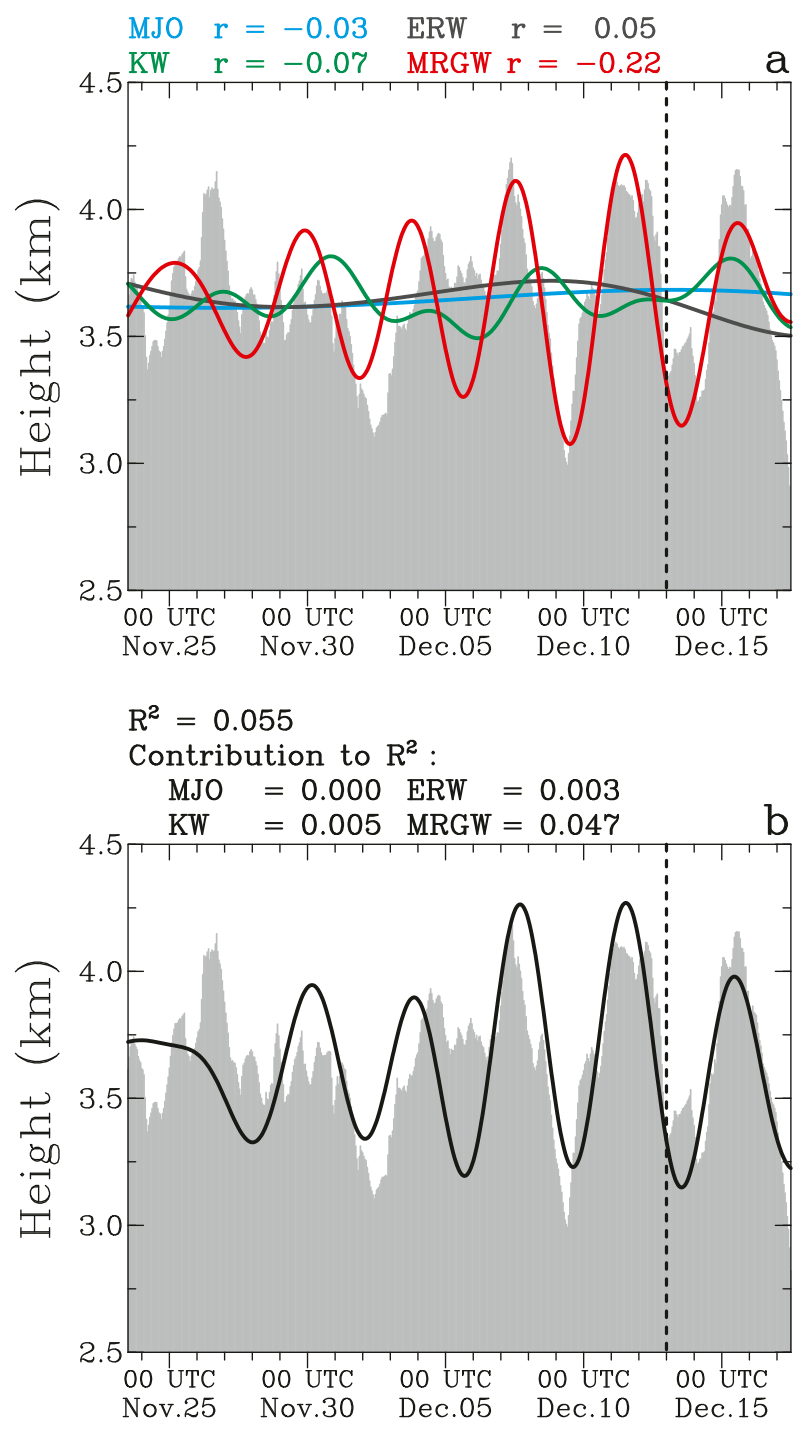

FIG. 17. As in Fig. 14, but for the 30-dBZ stratiform echo-top heights.

being $0 \%, 0.6 \%, 0.2 \%$, and $11.1 \%$, respectively. These results indicate that, similar to the areal variances of the convective echoes shown above (Figs. 10b and 11b), the variance of the convective rainfall was modulated predominantly by MRGWs. In contrast, the MJO event hardly affected the convective rainfall variance.

Figure 19 shows the regressed results of the stratiform volumetric rainfall. The MJO, ERW, KW, and MRGW indices were all significantly and negatively correlated with the stratiform volumetric rainfall (Fig. 19a), suggesting that these largescale disturbances can also enhance or suppress stratiform rainfall during their active or suppressed phases. These largescale disturbances contributed to $16.4 \%$ of the observed variance in the stratiform volumetric rainfall (Fig. 19b), which was approximately 1.4 times larger than their combined contribution 
Convective vol. rainfall
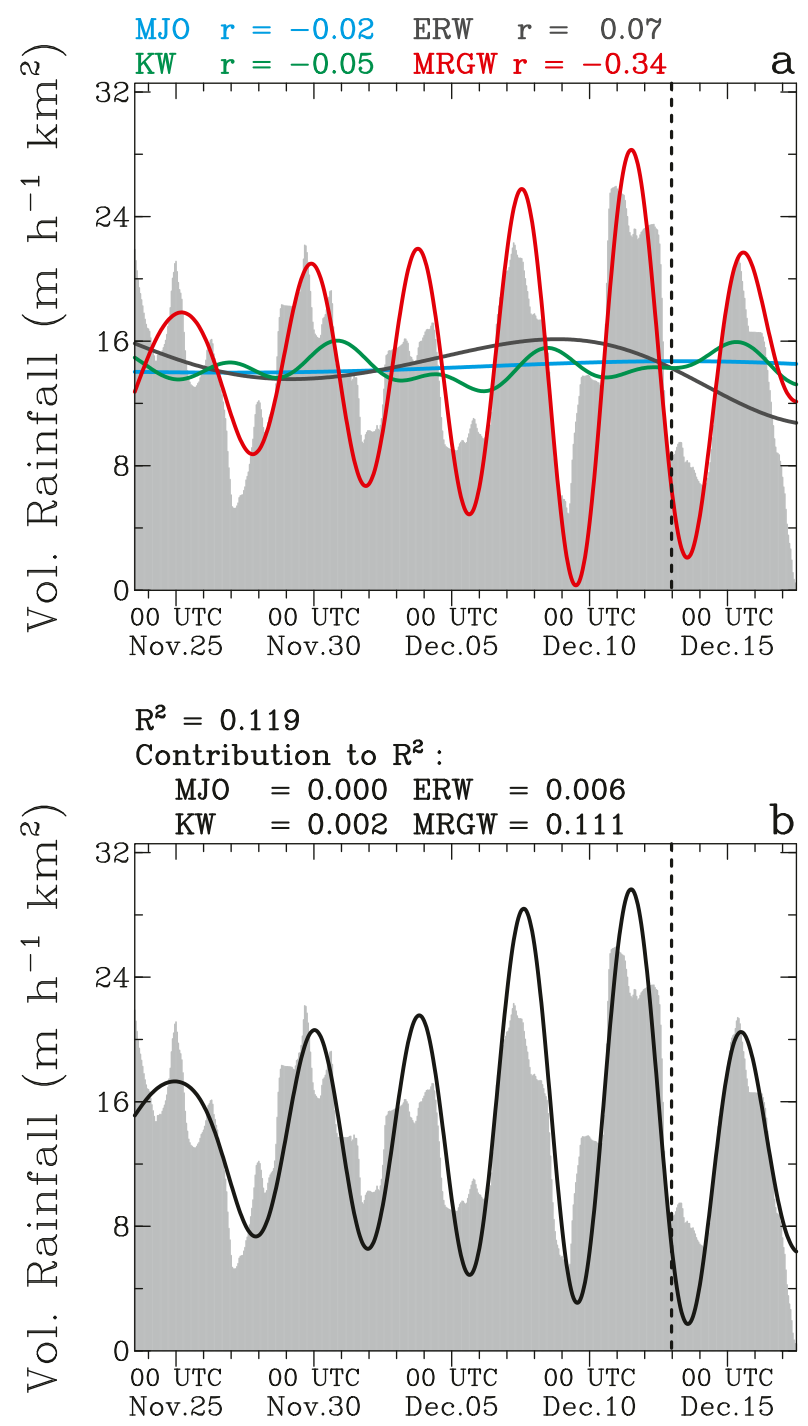

FIG. 18. (a) Time series of the regressed results for convective volumetric rainfall at $2 \mathrm{~km}$, based on an SLR analysis against the MJO index (cyan curve), the ERW index (dark gray curve), the KW index (green curve), and the MRGW index (red curve). The correlation coefficient $(r)$ for each index is shown at the top. (b) Time series of the regressed result for convective volumetric rainfall at $2 \mathrm{~km}$, based on an MLR analysis against all indices (black curve). The squared multiple correlation coefficient $\left(R^{2}\right)$ and the contribution of each index to $R^{2}$ are shown at the top. In both (a) and (b), the radar-observed convective volumetric rainfall after applying a 2-day running mean is shaded in gray. The vertical dashed line indicates the peak MJO date.

to the variance in the convective volumetric rainfall $(11.9 \%$, Fig. 18b). The percentage contributions of the MJO, ERW, KW, and MRGW indices to the stratiform volumetric rainfall variance were $1.6 \%, 0.6 \%, 4.6 \%$, and $9.6 \%$, respectively (Fig. 19b). Compared to convective volumetric rainfall (Fig. 18b), the contribution of the MRGW index to the variance of stratiform volumetric rainfall was relatively small, suggesting that the modulation of convective volumetric rainfall by MRGWs was more prominent than that of stratiform volumetric rainfall. However, the individual contributions of the MJO and $\mathrm{KW}$ indices to the stratiform volumetric rainfall variance increased, indicating that these disturbances tend to modulate stratiform volumetric rainfall.

For stratiform volumetric rainfall, the KW and MRGW indices contributed more than the MJO and ERW indices (Fig. 19b). Notably, the contribution of the MRGW index was at least twice as high as that of the KW index, indicating that MRGWs have the strongest impact on the variance of stratiform volumetric rainfall. The strong modulation of stratiform precipitation by MRGWs can be attributed to their strong modulation of convection (Figs. 10 and 11), which then matures and evolves into intense stratiform precipitation (Houze 1997). The fact that the MJO, ERW, and KW events contributed little to the variance of the convective echo areas implies that they modulate stratiform precipitation primarily via mesoscale ascent.

The influence of the large-scale disturbances on stratiform volumetric rainfall (Fig. 19) is similar to their influence on stratiform echo areas (Figs. 12 and 13), with the KWs and MRGWs largely responsible for the high-frequency variation, while the MJO and ERWs responsible for the low-frequency variation of stratiform volumetric rainfall. A comparison of Fig. 19b with Fig. 19a shows that stratiform volumetric rainfall is enhanced or suppressed by the superposition of the active or suppressed phases of these large-scale disturbances. It appears that the intense development of stratiform volumetric rainfall after the peak MJO date can be attributed to the superimposition of the active phases of the ERW, KW, and MRGW events on the active phase of the MJO event (Figs. 5 and 19b).

\section{d. MCS and sub-MCS populations}

The regressed results of the MCS population are shown in Fig. 20. Both the KW (-0.14) and MRGW (-0.16) indices were negatively and significantly correlated with the MCS population (Fig. 20a), indicating that the active phases of KWs and MRGWs facilitate the formation of MCSs. The percentage contribution of the large-scale disturbances to the MCS population variance was $4.1 \%$, with the $\mathrm{KW}(1.6 \%)$ and MRGW (2.1\%) indices being the two major contributors (Fig. 20b). In contrast, only a small contribution from the MJO index $(0.4 \%)$ and no contribution from the ERW index was observed.

As shown in Fig. 20a, MRGWs and KWs were largely responsible for the high-frequency variation of the MCS population. A comparison of Fig. 20b and Fig. 20a shows that the superposition of the active phases of MRGWs and KWs facilitates the formation of MCSs and vice versa during the superposition of their suppressed phases. In particular, the MCS population was relatively large around 15 December, when the active phases of the MRGW and KW events overlapped (Figs. 5c,d).

It is well known that the development of convection is indispensable to the formation of MCSs and those MCSs are often accompanied by extensive stratiform precipitation (Houze 2004). The regressed MCS results are consistent with the predominant contribution of MRGWs to convective development and the 


\section{Stratiform vol. rainfall}
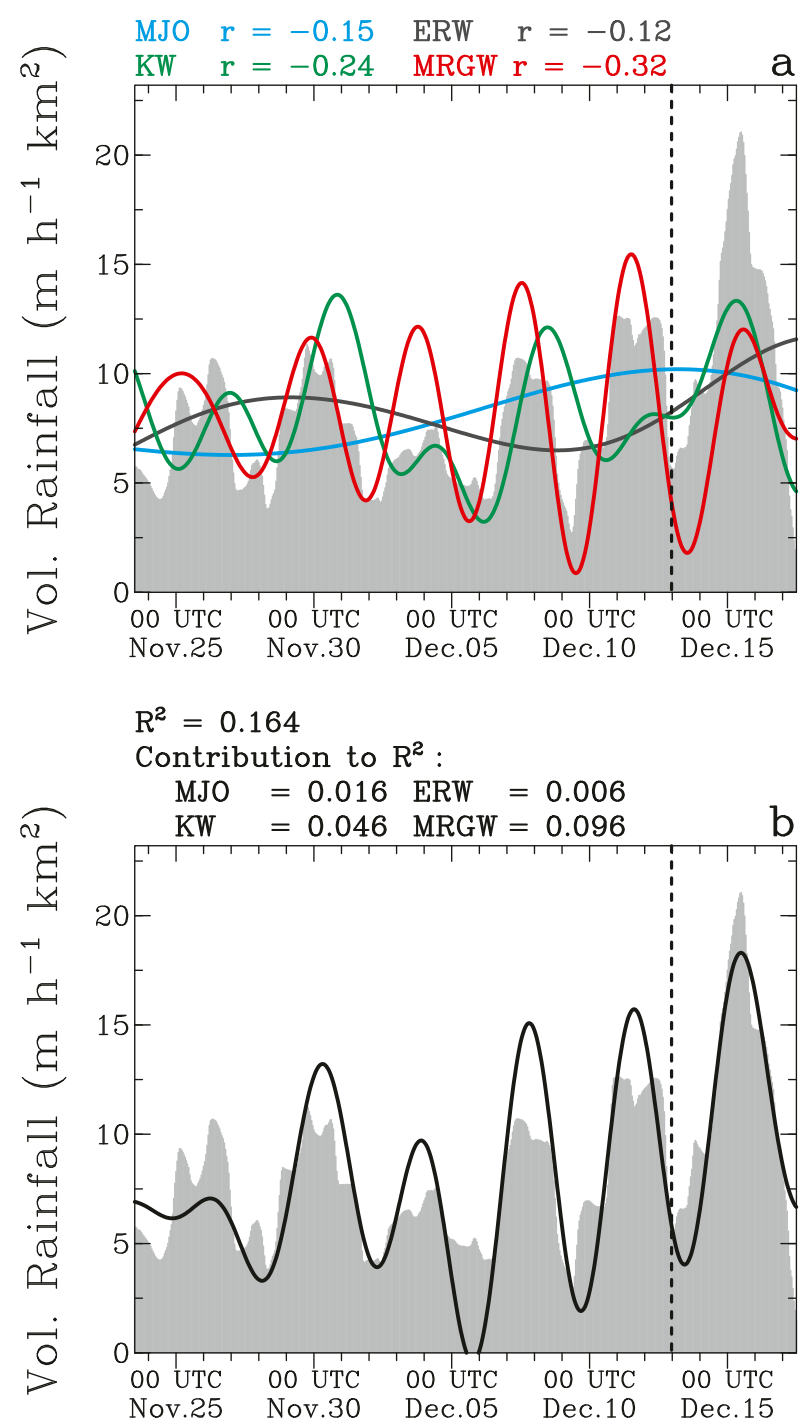

FIG. 19. As in Fig. 18, but for stratiform volumetric rainfall at $2 \mathrm{~km}$.

major modulations of MRGWs and KWs on stratiform echo areas (Figs. 10-13). As KWs only contributed minimally to convective development, it appears that the formation of MCSs was predominantly enhanced by MRGWs, with the superimposition of the active phases of MRGWs and KWs facilitating the growth of stratiform precipitation in MCSs.

Figure 21 shows the regressed results of the sub-MCS population. The correlation coefficients of the MJO $(-0.2)$, KW (-0.18), and MRGW (0.21) indices were statistically significant (Fig. 21a). It was noted that the MJO and $\mathrm{KW}$ indices were negatively correlated with the sub-MCS population, whereas the MRGW index was positively correlated with it, indicating that the formation of sub-MCSs tends to be enhanced during the active phases of the MJO and KWs, but during the suppressed phases of MRGWs. Figure $21 \mathrm{~b}$ indicates that $11 \%$ of the observed variance of the sub-MCSs population can be accounted for by the variances

\section{MCS population}
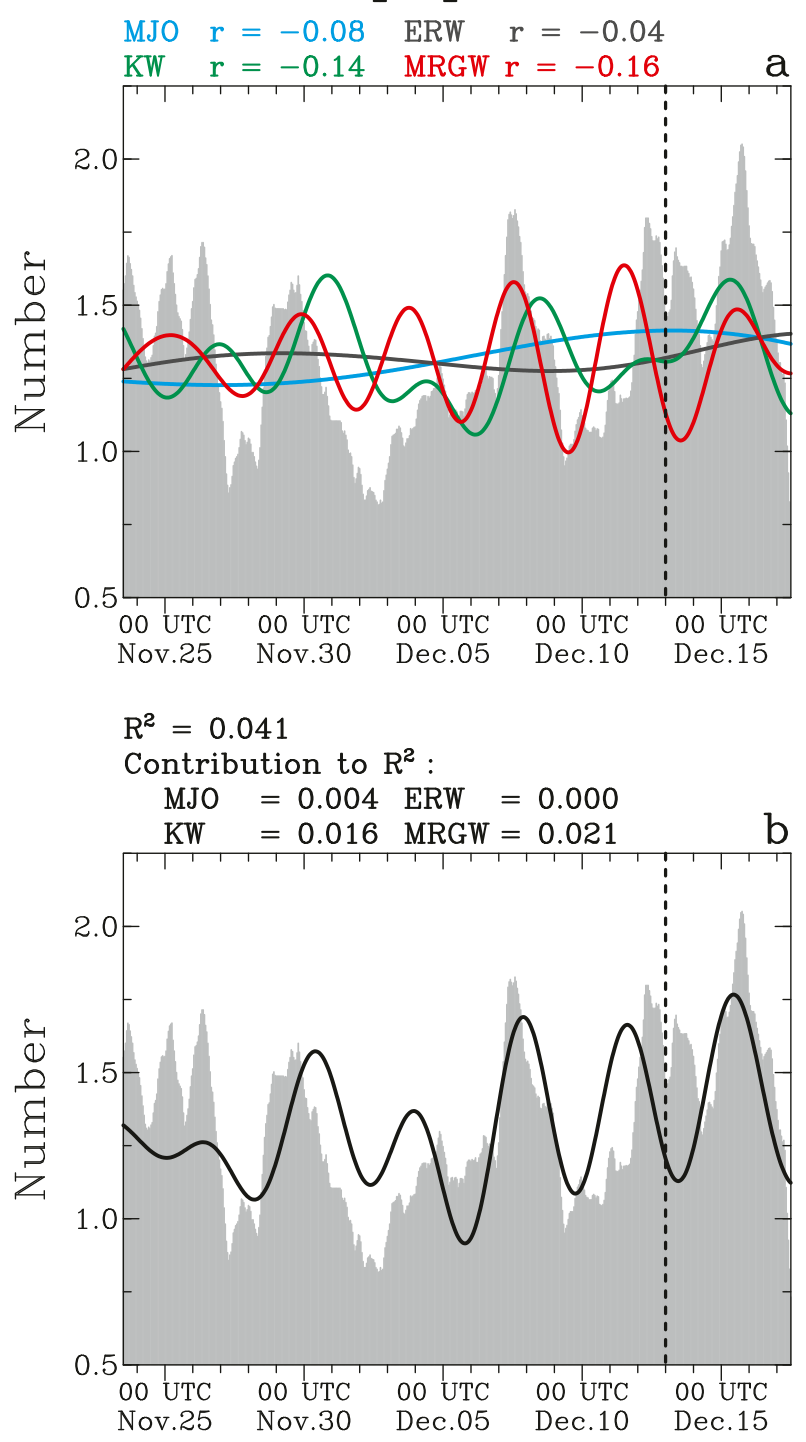

FIG. 20. (a) Time series of the regressed results for the population of MCSs, based on an SLR analysis against the MJO index (cyan curve), the ERW index (dark gray curve), the KW index (green curve), and the MRGW index (red curve). The correlation coefficient ( $r$ ) for each index is shown at the top. (b) Time series of the regressed result for the population of MCSs, based on an MLR analysis against all indices (black curve). The squared multiple correlation coefficient $\left(R^{2}\right)$ and the contribution of each index to $R^{2}$ are shown at the top. In both (a) and (b), the radar-observed population of MCSs after applying a 2-day running mean is shaded in gray. The vertical dashed line indicates the peak MJO date.

in the MJO (3.3\%), KWs (3.2\%), and MRGWs (4.5\%), with MRGWs possessing the maximum contribution.

Figure 21a indicates that KWs and MRGWs were largely responsible for the high-frequency variation, while the MJO contributed to the low-frequency variation of the subMCS population. A comparison of Fig. 21b and Fig. 21a shows that the enhanced formation of sub-MCSs around 


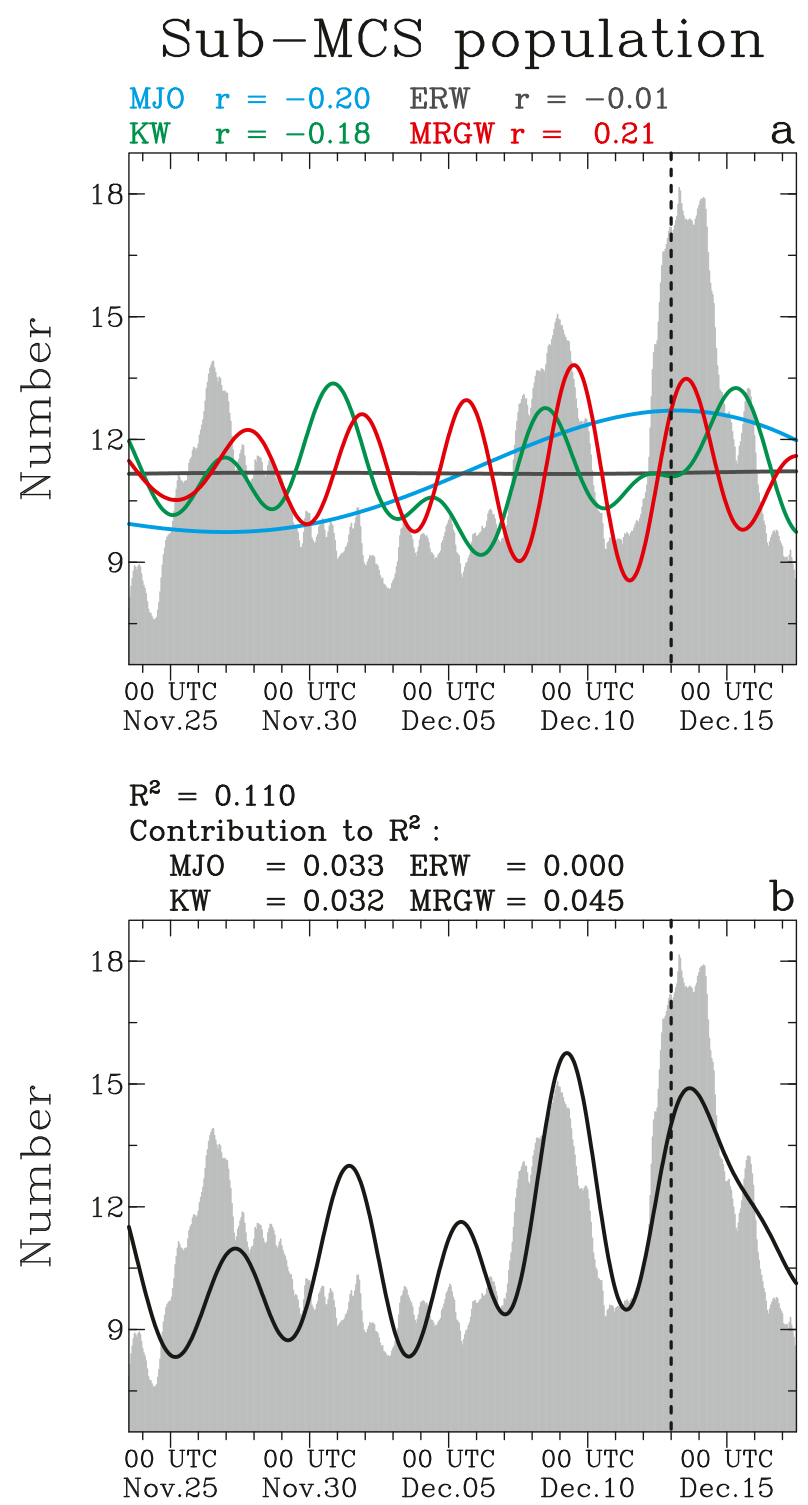

FIG. 21. As in Fig. 20, but for the population of sub-MCSs.

9 and 12 December can be attributed to the superposition of the suppressed phases of MRGWs with the active phases of the MJO and KWs (Figs. 5a,c,d). The enhanced formation of sub-MCSs during the suppressed phases of MRGWs is largely attributable to the predominant impediment of convective development by MRGWs during their suppressed phases (Figs. 10 and 11), which explains why the variation phase of the sub-MCSs was approximately opposite to that of the MCSs (Fig. 8).

\section{Discussion}

\section{a. Variability of precipitation morphology and rainfall}

The regressed results of echo areas, echo-top heights, volumetric rainfall, and MCS and sub-MCS populations against the indices of the MJO, ERWs, KWs, and MRGWs, as described in the previous section (Figs. 10-21), are summarized in Table 1. Except for the sub-MCS population, the majority of the variance of each radar-derived variable was found to be associated with one or two types of CCEWs, rather than with the MJO event investigated in this study. Thus, CCEWs can be key factors in modulating the multiple time-scale variability of precipitation morphology and rainfall within an MJO. Our results support the argument of Powell and Houze (2013), who emphasized that if an MJO event is superimposed by CCEWs, it is important to recognize and account for these individual waves. Given the well-known fact that MJO events frequently evolve with various CCEWs in their convective envelopes, the results of this study imply that $\mathrm{MJO}$ processes cannot be fully understood without ascertaining the distinct modulations of precipitation morphology and rainfall exerted by the CCEWs superimposed within the MJO convective envelope.

In particular, we demonstrated that the combined modulation of the MJO, ERWs, KWs, and MRGWs on the stratiform echo areas or volumetric rainfall was stronger than their combined modulation on the convective echo areas or volumetric rainfall (Figs. 10-13 and 18-19), which implies that the commonly observed dominant variability of stratiform precipitation areas and rainfall within an MJO (Lin et al. 2004; Morita et al. 2006; Barnes and Houze 2013; Powell and Houze 2013) can be caused by the dominant modulation of the MJO and CCEWs on stratiform precipitation. Furthermore, the variation of the convective echo-top heights larger than that of the stratiform echo-top heights (Figs. 7e-h) indicates that convective precipitation can dominate the variability in the vertical extent of convective activities during the active phase of an MJO. We also demonstrated that ERW and MRGW events exerted a great impact on the significant deepening and dropping of convective echo-top heights before and after the peak MJO date, respectively (Figs. 14 and 15), which implies that the superimposition of CCEWs within an MJO acts to produce a dominant vertical variability of convective activities during the active phase of the MJO. Given the important role of vertical variations of convective activity in modulating the vertical transport of heat and moisture associated with an MJO event (e.g., Katsumata et al. 2009; Lau and $\mathrm{Wu} 2010$ ), the results of this study highlight the impact of CCEWs on the convective progression of MJO events during their active phases.

\section{b. Limitations and future work}

This study could not investigate precipitation characteristics throughout the active phase of the MJO, because the stationary observation of the Mirai was terminated as scheduled on 17 December 2015, approximately 4 days before the transition from the active phase to the suppressed phase of the MJO (Fig. 5a). Although the regressed results as derived from Global Satellite Mapping of Precipitation (GSMaP) data (Kubota et al. 2007) throughout the active phase of the MJO (not shown) were similar to our results based on the stationary observation of the Mirai, the modulation of precipitation morphology by the MJO may not have been ascertained adequately using only the GSMaP data. In addition, the impacts of 
TABLE 1. Summary of the correlation coefficients $(r)$ and the contributions $\left(r^{2}\right)$ to the squared multiple correlation coefficient $\left(R^{2}\right)$ derived from the regression analysis against the MJO, ERW, KW, and MRGW indices. The bold numbers indicate correlation coefficients significant at the $99 \%$ level.

\begin{tabular}{|c|c|c|c|c|c|c|c|}
\hline & & & MJO index & ERW index & KW index & MRGW index & \\
\hline \multirow[t]{10}{*}{ Convective echoes } & \multirow[t]{2}{*}{$10-\mathrm{dB} Z$ echo areas at $2 \mathrm{~km}$} & $r$ & 0.01 & 0.05 & -0.07 & -0.31 & \\
\hline & & $r^{2}$ & $0 \%$ & $0.3 \%$ & $0.5 \%$ & $9.5 \%$ & $R^{2}=\sum r^{2}=10.3 \%$ \\
\hline & \multirow[t]{2}{*}{$30-\mathrm{dB} Z$ echo areas at $2 \mathrm{~km}$} & $r$ & 0.01 & 0.04 & -0.08 & -0.33 & \\
\hline & & $r^{2}$ & $0 \%$ & $0.2 \%$ & $0.5 \%$ & $10.7 \%$ & $R^{2}=\sum r^{2}=11.4 \%$ \\
\hline & \multirow[t]{2}{*}{ 10-dBZ echo-top heights } & $r$ & 0.03 & $\mathbf{0 . 3 0}$ & 0.09 & -0.23 & \\
\hline & & $r^{2}$ & $0 \%$ & $9.1 \%$ & $0.1 \%$ & $5.1 \%$ & $R^{2}=\sum r^{2}=14.3 \%$ \\
\hline & \multirow[t]{2}{*}{ 30-dBZ echo-top heights } & $r$ & 0.07 & 0.23 & 0.09 & -0.25 & \\
\hline & & $r^{2}$ & $0.3 \%$ & $5.2 \%$ & $0.2 \%$ & 6.1 & $R^{2}=\sum r^{2}=11.8 \%$ \\
\hline & \multirow{2}{*}{ Volumetric rainfall at $2 \mathrm{~km}$} & $r$ & -0.02 & 0.07 & -0.05 & -0.34 & \\
\hline & & $r^{2}$ & $0.0 \%$ & $0.6 \%$ & $0.2 \%$ & $11.1 \%$ & $R^{2}=\sum r^{2}=11.9 \%$ \\
\hline \multirow{10}{*}{ Stratiform echoes } & \multirow[t]{2}{*}{$10-\mathrm{dB} Z$ echo areas at $2 \mathrm{~km}$} & $r$ & -0.17 & -0.19 & -0.33 & -0.26 & \\
\hline & & $r^{2}$ & $2 \%$ & $2 \%$ & $8.8 \%$ & $6.1 \%$ & $R^{2}=\sum r^{2}=18.9 \%$ \\
\hline & \multirow{2}{*}{$30-\mathrm{dB} Z$ echo areas at $2 \mathrm{~km}$} & $r$ & -0.15 & -0.10 & -0.21 & -0.31 & \\
\hline & & $r^{2}$ & $1.9 \%$ & $0.4 \%$ & $3.3 \%$ & $9.1 \%$ & $R^{2}=\sum r^{2}=14.7 \%$ \\
\hline & \multirow[t]{2}{*}{ 10-dBZ echo-top heights } & $r$ & -0.02 & 0.19 & 0.04 & -0.2 & \\
\hline & & $r^{2}$ & $0 \%$ & $3.5 \%$ & $0 \%$ & $4.1 \%$ & $R^{2}=\sum r^{2}=\mathbf{7 . 6} \%$ \\
\hline & \multirow[t]{2}{*}{ 30-dBZ echo-top heights } & $r$ & -0.03 & 0.05 & -0.07 & -0.22 & \\
\hline & & $r^{2}$ & $0 \%$ & $0.3 \%$ & $0.5 \%$ & $4.7 \%$ & $R^{2}=\sum r^{2}=\mathbf{5 . 5} \%$ \\
\hline & \multirow[t]{2}{*}{ Volumetric rainfall at $2 \mathrm{~km}$} & $r$ & -0.15 & -0.12 & -0.24 & -0.32 & \\
\hline & & $r^{2}$ & $1.6 \%$ & $0.6 \%$ & $4.6 \%$ & $9.6 \%$ & $R^{2}=\sum r^{2}=16.4 \%$ \\
\hline \multirow{2}{*}{\multicolumn{2}{|c|}{ MCS population }} & $r$ & -0.08 & -0.04 & -0.14 & -0.16 & \\
\hline & & $r^{2}$ & $0.4 \%$ & $0 \%$ & $1.6 \%$ & $2.1 \%$ & $R^{2}=\sum r^{2}=\mathbf{4 . 1} \%$ \\
\hline \multirow{2}{*}{\multicolumn{2}{|c|}{ Sub-MCS population }} & $r$ & -0.2 & -0.01 & -0.18 & 0.21 & \\
\hline & & $r^{2}$ & $3.3 \%$ & $0 \%$ & $3.2 \%$ & $4.5 \%$ & $R^{2}=\sum r^{2}=11 \%$ \\
\hline
\end{tabular}

CCEWs and their interactions with the MJO on the regional contrast in the MJO convective envelope around the $\mathrm{MC}$ (Fig. 4) could not be revealed from the stationary observation of the Mirai. More comprehensive field campaigns, such as those proposed in YMC (Yoneyama and Zhang 2020), are required to provide insights to these issues, which would advance our understanding of the basic physical process of the $\mathrm{MC}$ barrier effect on MJO events.

The dominant contributions of CCEWs to the variation of convective activities (Table 1) imply that CCEWs can superimpose their own dynamic features on an MJO environment and act in combination with an MJO to modulate convective activities, which calls for future studies. In addition, this study has not examined the polarimetric variables obtained by the Mirai polarimetric radar. Therefore, future research is needed to investigate the correlation between precipitation microphysics and the superposition of the MJO and CCEWs, which would facilitate improved understanding of the precipitation characteristics of the MJO event.

\section{Summary and conclusions}

Variations in precipitation morphology and rainfall in relation to the simultaneous passages of an MJO event and CCEWs observed during the Pre-YMC period were analyzed using radiosonde, a C-band polarimetric radar, and globally merged $T_{b}$ data. The radiosonde and radar data were collected aboard the Research Vessel Mirai at $4^{\circ} 4^{\prime} \mathrm{S}, 101^{\circ} 54^{\prime} \mathrm{E}$ from 23 November to 17 December 2015. The radiosonde and $T_{b}$ data were used to identify the MJO and CCEW characteristics. Besides the MJO, two ERWs, five KWs, and six MRGWs were identified by filtering the $T_{b}$ data in the wavenumber-frequency domain. Simultaneously, the variation characteristics of precipitation morphology and rainfall were investigated from time series of radar-derived variables, including $10-$ and $30-\mathrm{dBZ}$ echo areas at $2 \mathrm{~km}, 10-$ and $30-\mathrm{dBZ}$ echo-top heights, and the volumetric rainfall at $2 \mathrm{~km}$ of both convective and stratiform echoes, and the MCS and sub-MCS populations. The convective activity associated with the MJO weakened near the equatorial region when it was crossing the $\mathrm{MC}$, which is consistent with the typical MC barrier effect on MJO propagation. The impacts of the MJO, ERWs, KWs, and MRGWs on the variances of precipitation morphology and rainfall were investigated by regressing each time series of radar-derived variables against the MJO, ERW, KW, and MRGW indices, defined as the time series of the filtered $T_{b}$ anomalies averaged over the observational site.

The main findings were as follows:

- The radar-derived variables exhibited both high-frequency variation on a time scale of 3-5 days and low-frequency variation on a time scale of more than 10 days. The KW and MRGW events were largely responsible for the high-frequency variation and the MJO and ERW events for the low-frequency variation.

- MRGWs were the disturbances that predominantly modulated convective echo areas, convective volumetric rainfall, and stratiform volumetric rainfall. In contrast, the MJO 
event had little influence on the variance of any of the convective variables.

- Stratiform echo areas and volumetric rainfall were more strongly modulated by the combined effects of the MJO, ERWs, KWs, and MRGWs than their convective counterparts. The substantial horizontal extension of stratiform echoes and the intense development of stratiform volumetric rainfall during the active phase of the MJO event were coherent with the superimposition of the active phases of all the analyzed CCEWs on the MJO event.

- ERWs and MRGWs were the dominant wave types in modulating echo-top heights, especially convective ones. MRGWs largely enhanced the vertical development of convective activities during their active phases and vice versa during their suppressed phases, whereas ERWs acted in a contrary manner to MRGWs. The strongest development and a significant reduction of convective echo-top heights before and after the peak MJO date, respectively, were coherent with the passages of ERWs and MRGWs.

- MCSs and sub-MCSs formed predominantly during the MRGW active and suppressed phases, respectively, which is consistent with the dominant modulation of convection by MRGWs.

The results of this study imply that the superimposition of CCEWs with an MJO event induces distinct variability of precipitation morphology, convective organizational mode, and rainfall on multiple time scales within the MJO event. In addition, our results suggest that the dominant modulation of stratiform precipitation by the MJO and CCEWs could be an important factor in the commonly observed dominant variability of stratiform precipitation during the active phases of MJO events. Furthermore, CCEWs act in combination to produce a dominant vertical variability of convection in coherence with the convective progression of MJO events during their active phases. The large-scale dynamics of MJO events and CCEWs, and their combined effects on the precipitation microphysical properties and convective progression of MJO events around the MC, need to be investigated further.

Acknowledgments. The authors wish to express their deep appreciation to all crew members of the Research Vessel Mirai and the technical staff of Global Ocean Development Inc. for their great support in conducting radiosonde and radar observations aboard the Research Vessel Mirai. We also thank the reviewers for their valuable comments and suggestions, which helped to improve this manuscript.

\section{REFERENCES}

Barnes, H. C., and R. A. Houze Jr., 2013: The precipitating cloud population of the Madden-Julian oscillation over the Indian and west Pacific Oceans. J. Geophys. Res. Atmos., 118, 69967023, https://doi.org/10.1002/jgrd.50375.

Cressman, G. P., 1959: An operational objective analysis system. Mon. Wea. Rev., 87, 367-374, https://doi.org/10.1175/15200493(1959)087<0367:AOOAS > 2.0.CO;2.

DeMott, C. A., B. O. Wolding, E. D. Maloney, and D. A. Randall, 2018: Atmospheric mechanisms for MJO decay over the Maritime Continent. J. Geophys. Res. Atmos., 123, 5188-5204, https://doi.org/10.1029/2017JD026979.
DePasquale, A., C. Schumacher, and A. Rapp, 2014: Radar observations of MJO and Kelvin wave interactions during DYNAMO/CINDY2011/AMIE. J. Geophys. Res. Atmos., 119, 6347-6367, https://doi.org/10.1002/2013JD021031.

Dickinson, M., and J. Molinari, 2002: Mixed Rossby-gravity waves and western Pacific tropical cyclogenesis. Part I: Synoptic evolution. J. Atmos. Sci., 59, 2183-2196, https://doi.org/10.1175/ 1520-0469(2002)059<2183:MRGWAW >2.0.CO;2.

Feng, J., T. Li, and W. Zhu, 2015: Propagating and nonpropagating MJO events over Maritime Continent. J. Climate, 28, 84308449, https://doi.org/10.1175/JCLI-D-15-0085.1.

Geng, B., and M. Katsumata, 2020: An algorithm for detecting and removing the spurious differential phase observed by C-band polarimetric radar in the rain. J. Meteor. Soc. Japan, 98, 585613, https://doi.org/10.2151/jmsj.2020-031.

,-- , and K. Taniguchi, 2020: Modulation of the diurnal cycle of precipitation near the southwestern coast of Sumatra by mixed Rossby-gravity waves. J. Meteor. Soc. Japan, 98, 463480, https://doi.org/10.2151/jmsj.2020-026.

Gottschalck, J., P. E. Roundy, C. J. Schreck III, A. Vintzileos, and C. Zhang, 2013: Large-scale atmospheric and oceanic conditions during the 2011-12 DYNAMO field campaign. Mon. Wea. Rev., 141, 4173-4196, https://doi.org/10.1175/MWR-D13-00022.1.

Guo, Y., X. Jiang, and D. E. Waliser, 2014: Modulation of the convectively coupled Kelvin waves over South America and the tropical Atlantic Ocean in association with the MaddenJulian oscillation. J. Atmos. Sci., 71, 1371-1388, https://doi.org/ 10.1175/JAS-D-13-0215.1.

_ D. D. E. Waliser, and X. Jiang, 2015: A systematic relationship between the representations of convectively coupled equatorial wave activity and the Madden-Julian oscillation in climate model simulations. J. Climate, 28, 1881-1904, https://doi.org/ 10.1175/JCLI-D-14-00485.1.

Holder, C. T., S. E. Yuter, A. H. Sobel, and A. R. Aiyyer, 2008: The mesoscale characteristics of tropical oceanic precipitation during Kelvin and mixed Rossby-gravity wave events. Mon. Wea. Rev., 136, 3446-3464, https://doi.org/10.1175/2008MWR2350.1.

Houze, R. A., Jr., 1997: Stratiform precipitation in regions of convection: A meteorological paradox? Bull. Amer. Meteor. Soc., 78, 2179-2196, https://doi.org/10.1175/1520-0477(1997) $078<2179$ :SPIROC $>2.0$.CO;2.

_., 2004: Mesoscale convective systems. Rev. Geophys., 42, RG4003, https://doi.org/10.1029/2004RG000150.

Janowiak, J. E., R. J. Joyce, and Y. Yarosh, 2001: A real-time global half-hourly pixel-resolution infrared dataset and its applications. Bull. Amer. Meteor. Soc., 82, 205-217, https:// doi.org/10.1175/1520-0477(2001)082<0205:ARTGHH> 2.3. $\mathrm{CO} ; 2$.

Jiang, X., and Coauthors, 2020: Fifty years of research on the Madden-Julian Oscillation: Recent progress, challenges, and perspectives. J. Geophys. Res. Atmos., 125, e2019JD030911, https://doi.org/10.1029/2019JD030911.

Katsumata, M., R. H. Johnson, and P. E. Ciesielski, 2009: Observed synoptic-scale variability during the developing phase of an ISO over the Indian Ocean during MISMO. J. Atmos. Sci., 66, 3434-3448, https://doi.org/10.1175/2009JAS3003.1.

Kiladis, G. N., K. H. Straub, and P. T. Haertel, 2005: Zonal and vertical structure of the Madden-Julian oscillation. J. Atmos. Sci., 62, 2790-2809, https://doi.org/10.1175/JAS3520.1.

, M. C. Wheeler, P. T. Haertel, K. H. Straub, and P. E. Roundy, 2009: Convectively coupled equatorial waves. Rev. Geophys., 47, RG2003, https://doi.org/10.1029/2008RG000266. 
Kim, D., H. Kim, and M. I. Lee, 2017: Why does the MJO detour the Maritime Continent during austral summer? Geophys. Res. Lett., 44, 2579-2587, https://doi.org/10.1002/2017GL072643.

Kubota, T., and Coauthors, 2007: Global precipitation map using satellite borne microwave radiometers by the GSMaP Project: Production and validation. IEEE Trans. Geosci. Remote Sens., 45, 2259-2275, https://doi.org/10.1109/TGRS.2007.895337.

Lau, K., and H. Wu, 2010: Characteristics of precipitation, cloud, and latent heating associated with the Madden-Julian oscillation. J. Climate, 23, 504-518, https://doi.org/10.1175/2009JCLI2920.1.

Lin, J.-L., B. Mapes, M. Zhang, and M. Newman, 2004: Stratiform precipitation, vertical heating profiles, and the Madden-Julian oscillation. J. Atmos. Sci., 61, 296-309, https://doi.org/10.1175/ 1520-0469(2004)061<0296:SPVHPA > 2.0.CO;2.

— IPCC AR4 climate models. Part I: Convective signals. J. Climate, 19, 2665-2690, https://doi.org/10.1175/JCLI3735.1.

Lubis, S. W., and C. Jacobi, 2015: The modulating influence of convectively coupled equatorial waves (CCEWs) on the variability of tropical precipitation. Int. J. Climatol., 35, 1465 1483, https://doi.org/10.1002/joc.4069.

MacRitchie, K., and P. E. Roundy, 2012: Potential vorticity accumulation following atmospheric Kelvin waves in the active convective region of the MJO. J. Atmos. Sci., 69, 908-914, https://doi.org/10.1175/JAS-D-11-0231.1.

Madden, R. A., and P. R. Julian, 1972: Description of global-scale circulation cells in the Tropics with a 40-50 day period. J. Atmos. Sci., 29, 1109-1123, https://doi.org/10.1175/15200469(1972)029<1109:DOGSCC > 2.0.CO;2.

Masunaga, H., 2009: A 9-season TRMM observation of the austral summer MJO and low-frequency equatorial waves. J. Meteor. Soc. Japan, 87A, 295-315, https://doi.org/10.2151/jmsj.87A.295.

Matsuno, T., 1966: Quasi-geostrophic motions in the equatorial area. J. Meteor. Soc. Japan, 44, 25-43, https://doi.org/10.2151/ jmsj1965.44.1_25.

Morita, J., Y. N. Takayabu, S. Shige, and Y. Kodama, 2006: Analysis of rainfall characteristics of the Madden-Julian oscillation using TRMM satellite data. Dyn. Atmos. Oceans, 42, 107-126, https://doi.org/10.1016/j.dynatmoce.2006.02.002.

Nakazawa, T., 1988: Tropical super clusters within intraseasonal variations over the western Pacific. J. Meteor. Soc. Japan, 66, 823-839, https://doi.org/10.2151/jmsj1965.66.6_823.

Powell, S., and R. A. Houze Jr., 2013: The cloud population and onset of the Madden-Julian oscillation over the Indian Ocean during DYNAMO-AMIE. J. Geophys. Res. Atmos., 118, 11979-11 995, https://doi.org/10.1002/2013JD020421.

Roundy, P. E., 2008: Analysis of convectively coupled Kelvin waves in the Indian Ocean MJO. J. Atmos. Sci., 65, 1342-1359, https://doi.org/10.1175/2007JAS2345.1.

—, and W. M. Frank, 2004a: A climatology of waves in the equatorial region. J. Atmos. Sci., 61, 2105-2132, https://doi.org/ 10.1175/1520-0469(2004)061<2105:ACOWIT>2.0.CO;2.

- , and $-2004 \mathrm{~b}$ : Effects of low-frequency wave interactions on intraseasonal oscillations. J. Atmos. Sci., 61, 3025-3040, https://doi.org/10.1175/JAS-3348.1.

—_, and C. J. Schreck III, 2009: A combined wave-number-frequency and time-extended EOF approach for tracking the progress of modes of large-scale organized tropical convection. Quart. J. Roy. Meteor. Soc., 135, 161-173, https://doi.org/10.1002/qj.356.

Rowe, A. K., and R. A. Houze Jr., 2014: Microphysical characteristics of MJO convection over the Indian Ocean during DYNAMO. J. Geophys. Res. Atmos., 119, 2543-2554, https:// doi.org/10.1002/2013JD020799.
Schlueter, A., A. H. Fink, P. Knippertz, and P. Vogel, 2019: A systematic comparison of tropical waves over northern Africa. Part I: Influence on rainfall. J. Climate, 32, 1501-1523, https:// doi.org/10.1175/JCLI-D-18-0173.1.

Straub, K. H., and G. N. Kiladis, 2002: Observations of a convectively coupled Kelvin wave in the eastern Pacific ITCZ. J. Atmos. Sci., 59, 30-53, https://doi.org/10.1175/1520-0469(2002)059<0030: OOACCK $>2.0 . \mathrm{CO} ; 2$.

- , and - 2003: Interactions between the boreal summer intraseasonal oscillation and higher-frequency tropical wave activity. Mon. Wea. Rev., 131, 945-960, https://doi.org/10.1175/ 1520-0493(2003)131<0945:IBTBSI >2.0.CO;2.

Swann, A., A. H. Sobel, S. E. Yuter, and G. N. Kiladis, 2006: Observed radar reflectivity in convectively coupled Kelvin and mixed Rossby-gravity waves. Geophys. Res. Lett., 33, L10804, https://doi.org/10.1029/2006GL025979.

Takayabu, Y. N., and T. Nitta, 1993: 3-5 day-period disturbances coupled with convection over the tropical Pacific Ocean. J. Meteor. Soc. Japan, 71, 221-246, https://doi.org/10.2151/ jmsj1965.71.2_221.

Wheeler, M., and G. N. Kiladis, 1999: Convectively coupled equatorial waves: Analysis of clouds and temperature in the wavenumberfrequency domain. J. Atmos. Sci., 56, 374-399, https://doi.org/ 10.1175/1520-0469(1999)056<0374:CCEWAO > 2.0.CO;2.

, — , and P. J. Webster, 2000: Large-scale dynamical fields associated with convectively coupled equatorial waves. J. Atmos. Sci., 57, 613-640, https://doi.org/10.1175/1520-0469(2000) $057<0613$ :LSDFAW $>2.0$.CO;2.

Wu, C. H., and H. H. Hsu, 2009: Topographic influence on the MJO in the Maritime Continent. J. Climate, 22, 5433-5448, https:// doi.org/10.1175/2009JCLI2825.1.

$\mathrm{Xu}, \mathrm{W}$., and S. A. Rutledge, 2014: Convective characteristics of the Madden-Julian oscillation over the central Indian Ocean observed by shipborne radar during DYNAMO. J. Atmos. Sci., 71, 2859-2877, https://doi.org/10.1175/JAS-D-13-0372.1.

, and - 2015: Morphology, intensity, and rainfall production of MJO convection: Observations from DYNAMO shipborne radar and TRMM. J. Atmos. Sci., 72, 623-640, https://doi.org/10.1175/JAS-D-14-0130.1.

,-- C. Schumacher, and M. Katsumata, 2015: Evolution, properties, and spatial variability of MJO convection near and off the equator during DYNAMO. J. Atmos. Sci., 72, 41264147, https://doi.org/10.1175/JAS-D-15-0032.1.

Yang, D., and A. P. Ingersoll, 2011: Testing the hypothesis that the MJO is a mixed Rossby-gravity wave packet. J. Atmos. Sci., 68, 226-239, https://doi.org/10.1175/2010JAS3563.1.

Yang, G.-Y., B. Hoskins, and J. Slingo, 2007: Convectively coupled equatorial waves. Part I: Horizontal and vertical structures. J. Atmos. Sci., 64, 3406-3423, https://doi.org/10.1175/ JAS4017.1.

Yasunaga, K., and B. Mapes, 2012: Differences between more divergent and more rotational types of convectively coupled equatorial waves. Part II: Composite analysis based on spacetime filtering. J. Atmos. Sci., 69, 17-34, https://doi.org/10.1175/ JAS-D-11-034.1.

Yokoi, S., S. Mori, M. Katsumata, B. Geng, K. Yasunaga, and F. Syamsudin, 2017: Diurnal cycle of precipitation observed in the western coastal area of Sumatra Island: Offshore preconditioning by gravity waves. Mon. Wea. Rev., 145, 37453761, https://doi.org/10.1175/MWR-D-16-0468.1.

Yoneyama, K., and C. Zhang, 2020: Years of the Maritime Continent. Geophys. Res. Lett., 47, e2020GL087182, https:// doi.org/10.1029/2020GL087182. 
Yuter, S. E., and R. A. Houze Jr., 1998: The natural variability of precipitating clouds over the western Pacific warm pool. Quart. J. Roy. Meteor. Soc., 124, 53-99, https://doi.org/10.1002/qj.49712454504.

Zhang, C., 2005: Madden-Julian oscillation. Rev. Geophys., 43, RG2003, https://doi.org/10.1029/2004RG000158. , and J. Ling, 2017: Barrier effect of the Indo-Pacific Maritime Continent on the MJO: Perspectives from tracking MJO precipitation. J. Climate, 30, 3439-3459, https://doi.org/10.1175/JCLI-D16-0614.1.
Zhu, Y., T. Li, M. Zhao, and T. Nasuno, 2019: Interaction between the MJO and high-frequency waves over the Maritime Continent in boreal winter. J. Climate, 32, 3819-3835, https:// doi.org/10.1175/JCLI-D-18-0511.1.

Zuluaga, M. D., and R. A. Houze Jr., 2013: Evolution of the population of precipitating convective systems over the equatorial Indian Ocean in active phases of the Madden-Julian oscillation. J. Atmos. Sci., 70, 2713-2725, https://doi.org/10.1175/ JAS-D-12-0311.1. 